\title{
Family structure effects on U.S. children's well-being? Re-examining the family instability hypothesis
}

\author{
Alejandra Rodríguez Sánchez
}

November 28, 2019

\begin{abstract}
Previous studies have shown that children who grow up in marriage-based twoparent families fare better in terms of their well-being than children who do not. Other researchers have instead argued that these negative effects are confounded by the children's parents characteristics affecting selection into specific family structure trajectories, which likewise affect the children's well-being. However, researchers have been unable to account for the complex and dynamic relation between the socioeconomic conditions of individuals and their trajectories of family formation and dissolution. Here I argue that even when researchers account for selection based on observable background characteristics, the negative effect of changes in family structure experienced during childhood on children's well-being may be biased. Exposure-confounder feedback bias may be present in this association in the form of time-varying confounders such as socioeconomic conditions which affect family transitions and are affected by them dynamically. Data from the Fragile Families and Child Well-being Study is used to empirically show this is the case. Family instability is here considered as a timevarying exposure. Estimations of effects of family transitions on multiple dimensions of children's well-being are obtained through estimation of doubly robust marginal structural models and inverse probability of treatment weighting. It is shown that most
\end{abstract}


of the effects of family instability are negative with a few noticeable exceptions. But more importantly, the paper shows that the size of these negative effects can be substantially reduced after partially accounting for an idiosyncratic selection of baseline background confounders and exposure-confounder feedback mechanisms. A discussion of these findings, as they relate to the association between socioeconomic conditions and contemporary family dynamics in the U.S., ensues.

Keywords: childhood; family demography; living arrangements; social inequality; causality. 


\section{Introduction}

It is often claimed that children who grow up in traditional, marriaged-based, two-parent nuclear families fare better in terms of their education, cognitive and socio-emotional development than children who spent some time in non-traditional, non-intact, non-normative families or "broken homes". Children are exposed to these, from here on, alternative familiy structures (AFS) when they are born out of wedlock in non-cohabiting relationships or to lone-mothers; or when their parents separate or divorce; or when they join other families to form blended, complex or stepparent families. Children in AFS, who currently are estimated to be around $30 \%$ in the United States (see Census Bureau (2019)), have been found to show worse outcomes in many dimensions of well-being than their peers in non-AFS. Such is what can be concluded from over a dozen systematic reviews on this topic: Wells and Rankin (1991), Amato and Keith (1991), Haveman and Wolfe (1995), Amato (2001), Jeynes (2006), Harris (2010), Amato (2010), Bernardi et al. (2013), McLanahan, Tach, and Schneider (2013), McWayne et al. (2013),Esping-Andersen (2016), Härkönen, Bernardi, and Boertien (2017), Saint-Jacques et al. (2017), and Hadfield et al. (2018). According to these, there is evidence for negative effects of family instability; but it is argued whether these effects can be given a causal interpretation; and furthermore whether there is effect heterogeneity by socioeconomic conditions.

Moreover, researchers have also considered that mere changes in family structure, as well as the type of changes (from a two parent to single-parent family v. from a single-parent to stepparent family), and the frequency or number of family transitions experienced, are causes of those negative effects. AFS have even been considered as an important and independent contributing factor to the perpetuation of poverty and inequality in the U.S. (McLanahan (2004)), particularly among African-americans and especially regarding racial-ethnic socioeconomic inequality. The family instability hypothesis (or FIH for short) was set out to address this. Supporters of the FIH claim that children in AFS will experience disruptions 
and instability in family structure (Cavanagh and Fomby (2019)). Given that changes in the family system require adaptation and adjustment in the roles and routines of their members; and that given that they imply a reduction in time and financial resources, changes in family structure will bring about stressful events in the life-course of adults and their children, which should, on average, negatively affect these last ones. Ever since the works of Moynihan (1965) and Coleman (1987) appeared, ${ }^{1}$ empirical investigations of hypotheses akin to the FIH have accumulated. Although the majority view claims such negative effects are present (i.e. at least for some childs and for some domains of children's well-being as surveyed in McLanahan, Tach, and Schneider (2013)), researchers still debate whether such statistical associations are yet another case of spurious correlation. That is that other factors affecting the propensity to changes in family structure drive these associations. There is empirical support for both of these positions (Fomby and Cherlin (2007)).

Critics of the FIH argue that the empirical association is not causal, because it is confounded by other factors that simultaneously affect family structure changes and children's well-being, arguing that no effect is present after appropriate controls, which account for selection into trajectories of instability or stability in family structures, are put into place (Bernardi and Boertien (2017)). Supporters of the FIH counterargue that, while confounding may exist in this association, after appropriately adjusting for it, there remains a negative, albeit smaller, effect of AFS on children's well-being (McLanahan, Tach, and Schneider (2013)); and that furthermore this empirical evidence is consistent across various outcomes related to children's well-being and has been found in other Western developed countries (Amato (2010)), which would lend more credence to the FIH.

However, both sides of the debate have overlooked a form of bias in the association between changes in family structure and children's well-being, which when accounted for may help researchers determine how, when and for what dimensions of children's well-being would AFS and family instability matter, if that is ever the case. This source of bias is refered to

\footnotetext{
${ }^{1}$ Which were carried out in the midst of an awareness of the changes and diversity of family life in U.S.
} 
as treatment-confounder feedback bias in the epidemilogical literature (Hernan and Robbins (2017, 247-55)), and in principle is present in studies assessing the effects of time-varying demographic behavior in longitudinal and cross-sectional data. For example, as is the case of the study of treatment of zidovudine on the survival probabilities of patients with HIV. This effect is biased because treatment allocation depends on a dynamic confounder which is affected by the treatment (i.e. treatment-confounder bias; Hernán, Brumback, and Robins $(2000))$.

Changes in family structure (i.e. the exposure or "treatment") have been shown to be causal factors for other explanatory variables in the family formation/dissolution process (Crosnoe et al. (2014)). For instance, separation or divorce lead to residential changes, to temporarily moving in with extended kin, to reductions in household income, as well as to increases in the labor force participation of mothers, among other things, which supposedly explain an important chunck of the effect of family structure (i.e. as mediators in the indirect effect story of the FIH; see Brand et al. (2019)). The problem is that those same changes resulting from the dissolution of a family, or the formation of a new one, may in turn affect family stability in subsequent time-points, making more likely to repartner or to remain without a partner, as it may result from moving to a low socioeconomic status and highly segregated inner-city neighborhood where rents are cheaper, or from entering new jobs with precarious working conditions (Hall, Iceland, and Yi (2019)). Therefore such changes will affect the instability of AFS, while simultaneously these same changes (i.e. now as confounders) will affect children's well-being as well (Mikolai and Kulu (2018), Jacoby et al. (2017), Perkins (2017) and Harding et al. (2010)).

But it is the double nature of these "intermediate" variables, as effects of changes in family life, as well as causes of further changes in family life, that is both as confounders and as mediators, what generates the bias when unadjusted for or inapropriately adjusted for in statistical analysis. The only known set of methods that can overcome this insidious form of bias are referred to as G-methods (see Mansournia et al. (2017) and Hernán and 
Robins (2006)). Lee and McLanahan (2015) discussed this issue and claimed that their estimates of negative effects on the socio-emotional domain among White children in a cohort of urban American families were robust to exposure-confounder feedback. But these authors accounted only for a restricted set of time-varying confounders that were affected by exposure, which poorly captures the complex dynamics of family life in the U.S.

In this paper I present an estimation of the effect of changes in childhood family structure using a doubly robust estimation of Marginal Structural Models (MSM) and Inverse Probability of Treatment Weighting (IPTW) accounting for a more complete set of exposure-confounder feedback mechanisms than the previous literature. The choice of these set of dynamic confounders is based on a causal reading of the FIH and the selection hypotheses. I assess the effects of family transitions on a variety of outcomes pertaining to different dimensions of children's well-being, using data from the Fragile Families and Child Well-being Study (FFCWS). I show that the FIH does a poor job in explaining differences between children in AFS, who were exposed to changes in family structure, and children who live in stable two-parent families. Exposure to changes in family structure does not affect the well-being of children, though some effects of little substantive significance are observed. Moreover, estimates of the effect of changes in family structure, especially in the behavioral or noncognitive, as well as the cognitive domains, may suffer from substantial unexplained bias. Small negative effects are found among children when they are around fifteen years old in their performance in school and some indicators of behavioral problems. But interpreting these effects as causal is troubled by the difficulty of properly controlling for long sequences of familiy structure trajectories with such little information; as well as by the likely presence of selection on unobservables, such as neighborhood effects, household wealth, and parental occupational achievement. If anything, this paper helps to make explicit the problems of estimating effects of family instability, but it doesn't fully solve these issues which future research should address. I conclude by proposing researchers to reconsider the place of socioeconomic determinants of family life dynamics in theorizing about family structure and 
its purported effects on children's well-being.

\section{Background}

\section{Narratives of family stress}

On the one hand, the notion of there being "fragile families" condenses the theoretical claim that the socioeconomic attainment of children is hampered by changes in family dynamics. The hypothesized negative impact of these changes on children's well-being stems from a deficit model which two main theories aim to explain: the family stress theory and new home-economics models of family investments (see Masarik and Conger (2017) and Browning, Chiappori, and Weiss (2014)). For economists in this research area, vulnerability of such families results from them being unable to fully benefit from the gains of marriage (e.g. Becker (1973) and Schultz (1974)). Negative effects on children's well-being result from a basic arithmetic operation: families without one parent have, on average, less financial and time resources than families in which the two biological parents are present. Such would be the case of single-parent households for example, but the FIH considers that blended, complex or stepparent families are still inferior to the traditional family structure because such AFS imply less investments in stepchildren's human capital formation, than what would be considered optimal. Among other reasons, according to these models stepfathers are assumed to lack the incentives to properly invest in their stepchildren and will, on average, invest less than what the biological father would have pressumably invested in, had he been present in the household (Browning, Chiappori, and Weiss (2014, 438-70)).

The family stress model further considers how the quality of interparental and parent-child relationship differs between AFS and traditional family structures. Parents' relationship quality, as well as their mental health, and parenting quality are presumed to be lower among AFS because in such configurations the roles of the single-parent or the stepparent ought to be negotiated anew, creating the potential for conflict in children who furthermore lack paternal 
sources of authority or attachment, and negatively affect mother's well-being, her health status, and her parenting skills. It is argued that not having a father present in the household also results in negative effects on children who lack positive masculine role models (SigleRushton and McLanahan (2004)). This story resonates well with a particular interpretation of AFS as incomplete institutions, that was developed by structural-functionalist researchers interested in the family (see Kingsbury and Scanzoni (2009, 207-10)). Under this perspective, AFS are not well suited to accomplish the societal regulatory functions and tasks that the traditional marriage-based nuclear family historically had in socializing individuals (but for an overview of the ideological origins and flaws of such a viewpoint see Coontz (2016)).

\section{Counter-narratives of family resilience and strength in the face of adversity}

Critics of the FIH, on the other hand, argue that negative effects are the result of background characteristics that make some individuals more prone to experience disruptions in their partnership trajectories. The selection hypothesis proposes that those factors, which are associated with changes in family structure, drive the negative association found in the data, in what causal analysis refers to as confounding (Jackson (2016)). Most contemporary studies on the FIH do consider these arguments and find that appropriate controls reduce the effect of changes in family structure, but that the negative effects, at least some of them, remain.

But selection bias is pervasive and also based on unobservables, for which in general social researchers cannot control for; and which, more importantly, has substantial consequences for how researchers theorize about dynamics of family life. For example, no study on the effects of changes in family structure has considered the effects of wealth of parents or their socio-occupational class, yet the decision to marry, to have children, and to stay married to a specific partner, may be affected by considerations of wealth or socio-occupational status attaintment. ${ }^{2}$ Both of these confounding factors affect the stability of the family trajectories

\footnotetext{
${ }^{2} \mathrm{Or}$ in the case of certain professions more prone to occupational homogamy (e.g. doctors), lack of
} 
of individuals because the cultural capital, economic capital or patrimony, acquired through marriage may be at stake in the case of a divorce. Individuals in specific social circles with high economic capital marry "because of their capital" and stay together "for their capital" (Bourdieu $(1993,35)$ ). On the opposite, lack of wealth or low socio-occupational attaintment may decrease the stability of familiy trajectories among those who had little to gain from marriage to begin with, and therefore little to lose from its dissolution. While at the same time wealth and socio-occupational class have been shown to be main determinants of children's well-being (Hällsten and Pfeffer (2017) and Downey and Condron (2016); and for other contextual factors see Fomby and Mollborn (2017)), which makes these and other unobserved variables confounders in the association between changes in family structure and children's well-being.

The selection hypothesis re-introduces agency into the theorizing on family dynamics. By refocusing the discourse on the sources of endogeneity (i.e. the decisions of agents that confound a hypothetical association and lead to self-select to out-of-wedlock childbearing or multi partner fertility; Fomby and Osborne (2017)) to conceive a much more complex process. But is possible to further extent this agency and assume that family structure trajectories result from a complex set of strategies involving multiple factors to which researchers barely have access to.

Here I argue that this is the case in the dynamics of family life in the U.S. Confounding is not only static, it is dynamic as well (Hernan and Robbins (2017, 247-55)). In response to changes in family structure, AFS can accomodate and compensate to earn in resources and time for their children by, for example, strategically reconfiguring their family composition; by moving in with extended kin; by changing their residence; by cutting on unnnecessary expenses and re-organizing their schedules; or by finding a new partner. In general, individuals in AFS find ways of compensating for the lost resources after a change in family suitable partners in the same profession, which makes repartnering within once own socio-occupational class unlikely after a divorce, discouraging individuals from divorcing in the first place. 
structure takes place (Erola and Kilpi-Jakonen (2017, 9-14)), but these changes are likely to further affect the formation of families (e.g. Cohen and Pepin (2018) and Lyngstad (2011)). Such complex feedback mechanisms more accurately describe the dynamics of family life, but they also shed light on the problems of dynamic confounding and exposure-confounder feedback bias, which I claim are present in the estimation of the effects of family transitions on children's well-being.

\section{Family dynamics from a life-course perspective}

Considering this, family dynamics result from the heterogeneity in the social and economic conditions in which demographic behavior of family formation and dissolution occur (Seltzer (2019)). For example, the question of interest, in counterfactual terms, is what would have children's well-being had been, had their biological mothers and fathers stayed together from birth until the moment where the children left the parental home. The conditional distribution researchers would like to know, but which remains unobserved, corresponds to $\mathbb{P}\left(Y_{t+1} \mid F_{t}=s^{\prime}\right)$ where $s^{\prime}$ is an unobserved state of family structure for children who experienced family structure $F_{t}=s$, and $Y_{t+1}$ is some measure of the child's well-being at a later point in time. ${ }^{3}$

But given the complexity of family dynamics in the U.S. (VanOrman and Scommegna (2016), Brown, Manning, and Stykes (2015)), childhood family structure may be more appropriately conceived of as a time-varying exposure or an "intervention" that unfolds over the life-course of children. Family structure may take various forms from birth until the time right before leaving the parental household (e.g. a child might be born to an unmarried couple that later separates, then spending a period with her mother, who may later start to live with

\footnotetext{
${ }^{3}$ Notice that this question relates to, but is not equivalent to, the effects of father absence. These correspond to a wholy different question than the effects of changes in family structure. For the former question runs into the problem of not appropriately defining a counterfactual, which makes estimation of causal effects impossible. Absent fathers are a heterogenous group, therefore one would have to ask which absent father should we talk about when the hypothetical present father can vary in terms of age, socioeconomic status, racial-ethnic background, personality, etc.
} 
a different partner who may become a stepfather figure, with whom the mother may have another child but from whom she may later separate). The trajectory of childhood family structure corresponds then to a sequence of states $\bar{s}_{\tau}=\left(s_{0}, s_{1}, s_{2}, \ldots, s_{\tau}\right)$, where at each measured time point $t$ a child is observed residing in one of a finite set of family structures, $s_{t} \in\left(s_{0}, s_{1}, s_{2}, \ldots, s_{\tau}\right)$, where each state is also known as the alphabet in the sequence analysis literature (Gauthier et al. (2010, 7)).

This sequence can be flexibly conceptualized to capture different aspects of the phenomena of family instability. For example, researchers might be interested in studying cumulative experiences of family instability, in which case a given sequence may look like $\bar{s}_{t}=(0,0,1,1,1,1, \ldots, 1)$ which captures the moment a family transition has occurred, regardless of whether further changes did not occur after the first transition; or researchers may be interested in changes at specific time points, as in $\bar{s}_{t}=(0,0,1,0,1,0, \ldots, 0)$; or even the number of changes as in $\bar{s}_{t}=(0,0,1,1,2,2, \ldots, 2)$; as well as the type of changes as in $\bar{s}_{t}=(T, T, S, S, B, \ldots, B)$ where $T$ stands for traditional nuclear family, $S$ stands for singleparent, and $B$ for blended, complex or stepparent families.

To make matters more clear, consider Figure 1 in which the main theoretical ideas behind the FIH and the selection hypothesis are represented in a directed acyclic graph (DAG). In this DAG, the measure of well-being $Y_{3}$ at time $t=3$ is a function $g$ (unknown) of the baseline invariant characteristics $W_{0}$, of parenting quality $P_{2}$, of the values taken by the time-varying charactersitics in $V_{2}$, and of unobserved variables $U$ that in turn, for simplification, affect all processes in the sequence $\left(Y_{3}=g\left(W_{0}, V_{2}, P_{2}, U\right)\right)$. The FIH focuses on the mediating effect of parenting related variables $P_{2}$, as well as the changes in resources captured by $V_{2}$; whereas the selection hypothesis makes emphasis on the arrows that go to $F_{3}$ and $Y_{3}$ from the unobserved factors $U$ and the observed baseline characteristics $B_{0}$. In this particular nonparametric model the null is assumed, so that no arrows go from changes in family structure at any time point to the measure of well-being, meaning that it is assumed that no effect of changes in family structure on children's well-being are present. 
Say then that one is interested in estimating the effect of changes in family structure on children's well-being $\left(F_{3} \rightarrow Y_{3}\right)$. An estimate of interest could be the difference between $Y^{\bar{s}}$ and $Y^{\bar{s}^{\prime}}$ which are the observed well-being measures for children who followed family trajectores $\bar{s}$ and $\bar{s}^{\prime}$ respectively. Given that one of these would be unobserved for children experiencing one particular sequence, researchers aim at estimating $\mathbb{E}\left(Y^{\bar{s}}-Y^{\bar{s}^{\prime}}\right)$. Assuming sequential exchangeability holds, which is required to interpret this estimated difference as a causal effect of exposure to different family trajectories, the expected value of this difference could be estimated from a random sample of children in the U.S. However, children who were exposed to one of these trajectories will likely differ in systematic ways on observed and unobserved characteristics from children exposed to alternative trajectories, therefore a causal interpretation is not warranted.

In other words, there are many backdoor paths that when inappropiately adjusted for, or unadjusted for, remain open; and these paths will bias the estimates of causal effects. If a statistical association between $Y_{3}$ and $F_{3}$ were tested against data generated by a specification of such a model, more likely than not a statistical association will be found even though there isn't one. And the challenge is to arrive at an estimate that does not give room to this spurious association. The effects of family structure or family transitions at any given time point after baseline $\left(F_{t}\right)$ will be biased when adusting only for baseline covariates $\left(W_{0}\right)$ that do not vary over time. But also by naively adjusting for time-varying confounders $\left(V_{t}\right)$ — as exemplified by the square around the nod representing this set of variablesthrough regression, stratification or matching, or by simply neglecting specific pathways, the theories and the empirical analysis induce the association in the data. On the contrary, unconfounded mediators, such as parenting skills, mother's psychological well-being, or the relationship quality between the mother and her child, which are captured by the node $P_{2}$ in the DAG, shall not be controlled for. Although affected by changes in family structure, these factors are assumed to be unrelated to further changes in family structure (or at least such link has not been specified in the literature) and may negatively impact the child's 
well-being. These mediating factors may be statistically confounded by yet other factors that complicate causal mediation analysis, but the important thing is that they do lie in the causal chain and supposedly explain the effect of repeated changes in family structure.

Assuming that this model corresponds to real existing mechanisms driving the dynamics of family life in the U.S. (as is done by the FIH and the selection hypothesis), it can be seen that the demographic behavior of family formation, as captured by the variable $F_{t}$, is endogenous (Ginther and Pollak (2004)). This means that childhood family trajectories are affected by other variables that are its causes and its effects, therefore confounders and mediators (or intermediate variables) at the same time. Causal effects of AFS or of changes in family structure on children's well-being are therefore dynamically confounded by the factors that affect the likelihood of this demographic behavior occurring over the life-course of children. Understanding what rules determine the realization of a particular trajectory of family structure is required in order to arrive at a consistent estimation of the causal effect of exposure to unstable or stable trajectories. Precisely trying to adjust for the factors that stochastically determine the sequence of family transitions is the core of the problem that this paper tries to address by means of a doubly robust strategy, as described in the next section.

\section{Data and Methods}

\section{Data}

The data used in this study corresponds to the Fragile Families and Child Well-being Study (FFCWS). In this study researchers have followed for over twenty years a cohort of American children that were born between the years 1998 and 2000 in U.S. cities with a population greater than 200,000 (Reichman et al. (2001)). The study is based on a probabilistic sample with a complex design in which cities, hospitals and beds in the selected hospitals were randomly and sequentially sampled, in order to arrive at a final sample of births. The 
FFCWS oversampled births to unmarried parents in order to obtain information about this specific demographic group. For an overview of the data response rates, sample weights and sampling designs see FFCWS (2019) and Kennedy and Gelman (2018). Here I make use of the data obtained at baseline and all other follow-ups, when children were one, three, five, nine and fifteen years old. Basic descriptives of the sample at baseline are given in Table 1.

\section{Alternative Family Structures (AFS) and family instability The effects of family} structure are usually examined by considering two different dimensions of family dynamics: First, the relationship status between the biological parents of the child; and second the presence or absence of the biological, or social, father. The first one considers the relationship status of the couple, as in married to, cohabiting with or in a relationship with the biological father, or as divorced/separated from the biological father, as well as widowed, or simply not in a relationship with him; whereas the second one refers to the entrance or exit of a biological or a social father into or out of the kinship family unit (i.e. the mother-child dyad). Here I followed these two notions of family structure in order to capture the phenomena of family instability, that to an extent agrees with and replicates the traditional operationalization of the concept, but as argued above this notion falls short in capturing the range of relationships a child might be exposed to and which may in actuality form part of their "normative" family (Raley et al. (2019)). I used the mother's relationship with the biological father of the child at each wave together with information on the relationship of the child to the people living in her household. ${ }^{4}$ If the mother was married to or cohabiting with the biological father of her child and lived in a household in which her partner was declared to be present, then I assumed these were the traditional nuclear two-parent families $(T)$. If she was married to or cohabiting with her partner, but did not live in a household with her partner present, then these were classified as living apart together $(L)$ families. If the mother was not in a relationship with the father of the child (i.e. in visiting relationship, they were friends, never

\footnotetext{
${ }^{4}$ It was not possible to distinguish between married and cohabiting couples, nor among blended, complex or stepparent families due to small sample sizes for more fine grained family structure typologies.
} 
or hardly talk, were divorced, separated or widowed, or had no relationship), and the mother did not live in a household with a partner present, then these were single-mother families $(S)$. Lastly, if the mother was not in a relationship with the father of the child, but lived in a household with a partner, then these were considered as blended, complex or stepfamilies $(B)$.

Figure 2 presents the prevalence of the fifteen most frequent childhood family structure trajectories in the FFCWS sample, plus the category of "Other" encompassing less frequent trajectories found in the data, that were observed at baseline plus the five follow-up timepoints. Three features can be observed: there is increasing variability as children get older; the sequences are quite complex from a statistical modelling point of view; and by the time children are nine years old, these "Other" trajectories are the most frequent category, more than the sum of the more stable ones that are depicted in the figure. This implies that heterogeneity is quite large and not enough numbers of children are captured following specific sequences to model changes in family structure within this small alphabet $\left(s_{t} \in\{T, S, B, L\}\right)$. To estimate $\mathbb{E}(Y \mid \bar{S})=\beta_{0}+\beta_{1} \operatorname{cum}(\bar{s})$, where $\operatorname{cum}(\bar{s})$ is the sequence of trajectories observed up to a specific time point to which the child was exposed to, and $\beta_{1}$ the total effect of changes in family structure, which is the parameter of interest, I operationalized changes in family structure as a dichotomous indicator variable that takes the value of one when the family structure at time $t$ differs from the one observed at $t-1$, and zero otherwise. Therefore the effects I estimate correspond to the most recent observed changes in family structure. ${ }^{5}$ As discussed above, the type and number of changes are of theoretical relevance as well, but such models are overtly complex and the factors that affect those specific selection routes are poorly understood. Besides that, one would need a very large sample to estimate the number of parameters corresponding to the observed sequences of family structure trajectories. Here I followed the more parsimonous approach, which should suffice to capture the negative effects according to the FIH.

\footnotetext{
${ }^{5}$ Between waves, especially those spread over years, multiple changes in family structure might have occurred that were no captured by these operationalization in the data.
} 
Baseline confounders and time-varying confounders/mediators To account for the endogeneity of demographic behavior in the estimation of effects of changes in family structure on children's well being, I included two sets of characteristis that may confound and bias the causal estimates, one for time-constant or baseline characteristics; and another one for time-varying characteristics. These two sets are however partial, meaning that other unobserved characteristics that confound the association still remain and selection bias cannot be discarded as an explanation.

Time-fixed confounders Women and men of certain characteristics might self-select into lone-parenthood or be more prone to divorce, or to re-partner, or may be exposed to restricted marriage markets, which limit their chances of finding a partner (see Lichter, Price, and Swigert (2019); Cohen and Pepin (2018); and Wilson (1987)). Some of those characteristics can also impact children's outcomes in systematic ways. For this reason I included a rich set of baseline characteristics observed at birth which are in line with what previous research has done (see Bernardi et al. (2013) for an overview): child's gender assigned at birth; lowbirth weight (yes or no); more than one baby born (i.e. twins; yes or no); whether mother consumed alcohol, tobacco or other drugs during pregnancy (yes or no); mother and father's ages at time of birth (discrete); their educational levels (less than high-school; high-school or GED; some college or technical education; and college or graduate education); their self-assigned racial-ethnic categories (White, non-hispanic; Black, non-hispanic; Hispanic; and other); their religiosity (frequency of religious attendance); their migration background (i.e. were you born in the United States; yes or no); their self-rated health (poor or fair health v. good, very good or excellent); whether mother or father grew up with both of their respective parents (yes or no); whether father had ever been in jail (yes or no) and whether the mother had thought about having an abortion or the father had suggested having one to the mother (yes or no). Additionally, mother's cognitive abilities, as captured by the Peabody Picture and Vocabulary Test (PPVT) at the third wave, assuming that such a 
variable does not change over time.

Time-varying confounders Additionally, effects of family transitions can be dynamically confounded by time-varying confounders and by exposure-confounder feedback. There is little knowledge about which factors affect the probability of a couple experiencing a given family structure trajectory. The most studied transition is divorce or separation for which many factors have been found to be associated (Härkönen (2014)); or regarding the formation of blended, complex or stepparent families (Saint-Jacques et al. (2017)). Other transitions, like transitions between household structures, are understudied (Perkins (2017)). Notwithstanding, I selected a set of time-varying factors that are likely contributing to changes in partnership trajectories of mothers in causal ways, based on previous research.

Income to poverty ratios, changes in residence, rents and mothers' labor force participation:

Parental resources in time and money are considered as affected by divorce and may further affect family formation in subsequent time-points. I included the income to poverty ratio categories, based on the equivalent household income at each wave (i.e. constructed by the survey organizers, it includes income from all sources). Family transitions also lead to changes in residence and neighborhoods, especially when cheaper rents are sought. To account for this I included changes in residence with respect to the previous wave (yes or no) and whether the mother currently rents or owns the place she lives in. Finally, changes in family structure may also increase the labor force participation of women (Cohen (2002)) and I included an indicator for having a job in the current wave. ${ }^{6}$

\section{Demography of the household: extended kin and siblings}

Living arrangments are also affected by changes in family structure (Jæger (2012)). In contexts where housing is unaffordable (Desmond and Perkins (2016)), experiencing changes

\footnotetext{
${ }^{6}$ Wealth, which is also affected by family transitions and will likely affect subsequent family stability was not observed in the sample.
} 
in family structure may push people to rellocate with other relatives or friends (Desmond and Perkins (2016), Raley et al. (2019)). I compared households in nuclear (child lives only with one or two of her parents, with or withousiblins siblings) v. extended (child lives with further extended kin, like grandparents, aunts or cousins; it may be one or two parents and with or without siblings) or composite (child lives with people who are unrelated to her; it may be with one or two parents and with or without children). Other changes in living arrangements that may result from changes in family structure are the presence of stepsiblings from other relationships. I included an indicator for presence of mother-side siblings in the household.

\section{Intrafamiliar violence:}

Finally, intrafamiliar violence is clearly an experience that will trigger changes in family structure and may also affect the child's well-being (Straus (2017)). I included an indicator of whether mother reported that her partner (i.e the biological or social father, or any current partner) had verbally or physically abused her.

This selection of household level characteristics which may function as dynamic confounders are in line with the work of Lee and McLanahan (2015), but remains idiosyncratic. Besides the characteristics these researchers considered, I added an interaction between changes in residence and living on rent to improve the specification of these models. I excluded variables representing changes in psychological well-being of mothers, such as depression, or parenting quality, or relationship quality, because these correspond to pure mediators according to the FIH, and should not be controlled for in the estimation of the total effect of family transitions.

Measures of child's well-being I looked at a broad selection of child well-being indicators, taking advantage of the rich information in the FFCWS and considering that the effects of AFS and family instability are hypothesized to affect child well-being, and that they have been observed for many dimensions of this construct. I classified these in three 
broad categories: a) health related; b) behavioral, noncognitive or executive function types; and c) educational or cognitive. Table 4 in supplementary material presents an overview of these different outcome variables and basic descriptive statistics.

\section{Health:}

From the moment children were one year old, mothers were asked at each follow-up survey whether a doctor had diagnosed the child with asthma. I constructed a dichotomous indicator when mothers responded affirmatively to this question; with no diagnosis of asthma as the reference category. Children's BMI, standardized by age and gender, was calculated when children were three, five, nine, and fifteen years old by the FFCWS. Based on this calculation, I constructed a dichotomous indicator for overweight or obesity in childhood, defined as those children's BMIs that were above the 85th percentile of the distribution of weights for each year. At the 6th wave, to assess healthy behavior, I constructed a dichotomous indicator which captures whether children, already in their teeange years, had tried alcohol, tobacco or any other drug or substances, with no use of any substance as the reference category.

\section{Behavioral Ratings and non-cognitive domain:}

At the second wave, child's emotionality and shyness were assessed by means of mothers' ratings on a subset of questions taken from the EAS Temperament Survey for Children (Mathiesen and Tambs (1999)). Emotionality refers to irritability or anger; whereas shyness is related to behavior with strangers. Both constructs are said to be associated with later anxiety and depression in young adulthood. I use maternal ratings on six items (three for emotionality and three for shyness) on a five level scale to show how characteristic a specific behavior was in her child (from 1 being "not characteristic or typical of your child" until 5 being "very characteristic or typical of your child"). Child Behavior Problems were assessed at the third, fifth, ninth and fifteenth follow-ups. These are based on different subsets of questions from the Child Behavior Checklist 2-3 (Koot et al. (1997)). Again maternal ratings were used on a three level scale indicating whether a given item was not true (0); sometimes 
or somewhat true (1); or very true or often true (2) of her child. Two additional measures of behavior in school were included for when children were fifteen years old. If the child had ever been expelled or suspended from school and the trouble at school scale, which consists of a series of statements about situations that may occur to the child related to school (paying attention at school, getting along with classmates and teachers, and getting homework done) evaluated on a scale from never $(=0)$ to every day $(=4)$. For all these constructs I calculated a total score by adding the individual items in each scale.

\section{Cognitive development and educational achievement:}

The PPVT was also assessed when children were three, five and nine years old (Hodapp and Gerken (1999)). This standardized assessments measures the verbal abilities of children in English and is considered as an indicator of cognitive development. At the sixth wave, teens were asked about their grades (i.e. A, B, C, D or lower, no grade or pass/fail only) obtained at the most recent grading period in the subjects of English or language arts, mathematics, history, and science. I constructed four dichotomous indicators for the events of obtaining a grade of $\mathrm{C}$ or lower in each of these classes. Finally, the event of having ever failed a class, also as a dichotomous indicator, was considered as an additional measure of educational achievement. ${ }^{7}$

\section{Methods}

In general, the family structures that a child experiences are the result of dynamic treatment trajectories. The correct specification of the rule that "assigns" children to a specifc exposure trajectory is unknown, but not accounting, at least partially, for the complex selection process that leads to experiences of family instability may overestimate the effects of family transitions on children. These selection process can be hypothetically summarized by a rule

\footnotetext{
${ }^{7}$ Some of the health and cognitive outcomes may be considered as partly behavioral or non-cognitive, and partly cognitive, so the classification is not entirely clear. For example obtaining good grades in school requires both cognitive and non-cognitive skills, as well as not engaging in bad health behaviours does.
} 
$F_{t}=g\left(\bar{s}_{t-1}, \bar{v}_{t-1}, w_{0}\right)$ in which the family structure $F_{t}$ a child will experience is a function of the past history of family structures up to $t-1\left(\bar{s}_{t-1}\right)$; the vector of time-varying confounders history $\bar{l}_{t-1}=\left(v_{o}, v_{1}, \ldots, v_{t-1}\right)$ up to time $t-1$; and on time-constant confounders observed at baseline $w_{0}$ (in which it is assumed all relevant varibles are observed). Based on this considerations and the non-parametric model presented in Figure 1, I estimated a doubly robust marginal structural model (MSM) with inverse probability of treatment weighting (IPTW).

MSM serve the goal of modeling the marginal distribution of the unobserved potential outcomes in data when time-dependent exposure, time-dependent confounding, and exposureconfounder feedback effects are present. IPTW is then used to estimate the parameter of interest. It will provide unbiased estimates in the case of dynamic confounding and exposureconfounder dependencies, under the assumptions of sequential exchangeability, positivity and consistency. This last assumption only holds if models of the selection into the family structure (i.e. the propensity models) are correctly specificied. Given the little knowledge there is on what factors drive such transitions between states in a family structure trajectory, this assumption probably does not hold. A doubly robust version may help in reaching consistency. This doubly robust model uses the IPTW to reweight the sample of children together with a regression model for the outcome variables in which baseline covariates determining the outcome are included, to arrive at a weighted regression model that will have higher chances of capturing the effect if the adjusted outcome regression model or the propensity score model, or both, are correctly specified (Kang, Schafer, and others (2007) showed this estimates to perform better in terms of accuracy than other alternatives even when both models are misspecified in a related task of dealing with missing information).

I used stabilized weights $\left(s w_{i}^{t}\right)$ to account for the low probabilities of children whose parents follow specific trajectories of changes in family structure in the sample up to time $t$, where

$$
s w_{i}^{t}=\frac{f\left(s_{t} \mid \bar{s}_{t-1}, w_{o}\right)}{f\left(s_{t} \mid \bar{s}_{t-1}, \bar{v}_{t-1}, w_{o}\right)}
$$


for a sample of $i=1, \ldots, N$ children, $t=1,2,3, \ldots, \tau$ time-points, and where $f$ corresponds to the conditional distribution of the exposure at time point $t$. First, propensity score models are used to estimate this conditional distribution for the event of changing family structure between follow-up surveys $t$ and $t-1$. For the probabilities in the numerator, I used prior changes in family structure and baseline family structure, together with baseline confounders that do not change over time. For the denominator, information on the history of previous changes in family structure, all time-varying confounders up to $t-1$, and baseline confounders were used. In both cases I used a generalized linear model with a logistic link function. These models included interaction terms between mother's age and low-weight birth, between racial/ethnic categories and educational level (for both mothers and fathers), between poverty categories and racial/ethnic categories, and finally between having moved houses and living on rent. These interaction terms improved in general the specification of the drivers of transitions ${ }^{8}$.

Second, to account for loss to follow-up, an additional censoring model with baseline covariates was estimated to compute IPTW that accounts for the probability of droping out at each follow-up (i.e. avoiding selection bias). From these estimated models I obtained the predicted probabilities of changing family structures between each follow-up survey and censoring, and combined them appropriately to form the stabilized weights obtaining $s w_{i}^{\tau}=s w_{i}^{0} \times s w_{i}^{1} \times \ldots \times s w_{i}^{\tau} \times c_{i}^{\tau}$ where $\tau$ is the time-point at which effects on children's well-being are estimated. Although no extreme weights were obtained following this methodology, all weights were truncated at the 1st and 99th percentiles (descriptives of the weights are provided in Table 5 in the supplementary material section)

Third, for dichotomous outcomes I estimated linear probability models (LPM) with correction for robust standard errors (SE) to account for heteroskedasticity. The sample parameter estimates of these models can be interpreted as risk differences (RD) or average marginal effects (AME). Positive values of estimates mean that the probability of the outcome is higher

\footnotetext{
${ }^{8}$ Results not shown in the paper due to space limitations
} 
for children experiencing changes in family structure, whereas for negative estimated coefficients the probability is lower. For outcomes based on standardized questionnaires, ratings and assessments, I also estimated linear models in order to make the results comparable to the existing literature. ${ }^{9}$ I considered a standaridzed or rescaled version of the total score on each instrument so that parameter estimates may be interpreted as standaridzed coefficients and compared across time-points. For the estimates of the IPTW, robust bootstrap standard errors were computed as suggested by Austin (2016), with 250 bootstrap resamples.

The average percentage of missing information in the analytical variables was around $16 \%$. To address the bias due to missing information, I used multiple imputation by chained equations (Van Buuren and Oudshoorn (1999)) with a total of $M=56$ imputations. The imputation model used the CART algorithm (Burgette and Reiter (2010)) to find the best set of predictors among the analytical variables to impute the data using all information available across waves, with 20 iterations per imputation. All inferential results make use of the sampling weights using the methodology of replicate weights explained in FFCWS (2019) which account for the oversampling of births to non-married mothers.

Finally, a causal interpretation of the doubly robust IPTW estimates relies on further assuming that no further unmeasured confounders remain. But as argued in the background section, this assumption is strong in light of neighborhood effects (Sharkey and Faber (2014)), parental wealth (Hällsten and Pfeffer (2017)) and the socio-occupational achievement of parents (Downey and Condron (2016)), to name a few of potential confounders which remain unobserved in this paper. However, by considering a more complete set of time-varying con-

\footnotetext{
${ }^{9}$ It is assumed that no systematic measurement error affects the outcomes, but limitations of the paper discuss this possibility. Although commonly mistaken for metric or continuous variables (i.e. as interval or ratio scales), the scales based on the number or correct responses on standardized assessments (even if weighted by an item response theory model); or the sum of ratings given on a likert-type scale; only provide ordinal information. The scores on these scales order individuals along an assumed continuous distribution of the hypothetical and unobserved construct, but do not inform about distances between them on the construct. Furthermore they do not provide any evidence that the hypothesized construct constitutes a quantitative attribute that can be quantified on any scale, evidence of that does not exist in the psychological literature on which those instruments are based. I did an alternative analysis of this by using percentiles splits, results not shown.
} 
founders, by using MSM, and by examining various outcomes, the paper is able to re-examine the explanatory potential of the FIH

\section{Results}

\section{Descriptives}

Table 1 presents descriptive characteristics of the FFCWS sample at baseline. There are clear differences between children born to married or cohabiting parents $\mathrm{v}$. those born to single-mothers or in blended, complex or stepparent family configurations (those born to LAT family structures are in contrast more similar to the married/cohabiting parents). "Fragile families" are predominantly formed by young and low-educated parents, mostly of non-hispanic black and hispanic racial/ethnic backgrounds. They are more likely to live in with extended or unrelated kin, and are more affected by poverty than traditional nuclear two-parent families. This holds true across all time-points where I consider changes in family structure. ${ }^{10}$

\section{Propensity score models}

There are not only theoretical reasons to believe that variables affected by family transition may affect the chances of subsequent future family transitions. The FFCWS sample suggest this to be at play in the dynamics of family life in the U.S. Table 2 presents estimates of relative risks $(\mathrm{RR})$ for the event of experiencing changes in family structure between waves for the set of time-varying confounders discussed in the previous section $\left(L_{t-1} \rightarrow S_{t}\right)$. I obtained these estimates by fitting a log-linked binomial model and exponentiating the obtained coefficients, obtaining in this way ajusted RR. ${ }^{11}$ These estimates do not constitute

\footnotetext{
${ }^{10}$ Descriptives of the sample at each follow-up time show this to be the case, but I left them out of the paper because of space limitations

${ }^{11}$ These models additionally control for all baseline characteristics.
} 
an empirical test of the causal hypotheses of dynamic confounding and/or the exposureconfounder feedback mechanisms; they are merely suggestive of such causal linkages because they might be affected by unobserved confounders in turn. Such tests would require their own independent investigation, which is left for future research.

What is remarkable however is that the adjusted RR point in the expected direction. For example, for indicators of residential instability, experiencing intrafamiliar violence and living with extended kin, the adjusted RR are always higher than one at all follow-ups, meaning that these events increase the chances of children experiencing further family transitions in their life-course; whereas presence of siblings from the mother side in the household and lower levels of poverty have RR that are systematically less than one, implying less chances of experiencing further family transitions than children without siblings or affected by poverty. Other time-varying covariates do not behave so systematically across all time periods. The estimated models are however imprecise. Effect sizes are small and, with a few noticeable exceptions, the estimated confidence intervals always include a $R R=1$; but regarding the consistency of their direction across time, they are at least suggestive.

Moreover, as arguably is the case of family transitions, changes that are a consequence of family disruption or repartnering, such as changes in income or in residence, or decisions to move in with extended kin, etc., further create imbalances in the sample. This can be seen in the supplementary material where in Figure 7 it is shown that average standardized mean differences (ASMD) for these time-varying covariates are larger for family transitions that occur at later ages, meaning that dynamic confouding and exposure-confounding feedback may affect the validity of the sequential exchangeability assumption even further.

Considering this, Table 3 shows the prevalence of unstable and stable families at each followup by the family structure that was observed in the previous wave. There are enough cases of children experiencing changes in family structure at each follow-up, to reliably study the effects of these changes on children. But as discussed above, families of children 
exposed to family instability differ in systematic ways from unexposed children in background and in time-varying characteristics. Given that sequential exchangeability does not hold, only appropriately adjusted estimates of the differences between children exposed to family transitions and unexposed children may be interpreted as causal effects.

These concerns are partly confirmed by the estimation of the "average treatment effect" of familiy transitions through the doubly robust estimates based on the MSM and the IPTW in comparison to the unadjusted or the baseline confounder adjusted estimates. In general, the estimates of the unadjusted effect, which for most outcomes show the well-known negative association between changes in family structure and children's well-being, are substantially reduced by the inclusion of baseline confounders; and slightly further reduced by consideration of the dynamic interplay of time-varying confounders and time-varying exposure, with a few noticeable exceptions that are discussed in the following.

\section{Health outcomes}

In the health domain, my estimates do not fully resonate with the FIH, nor with the selection hypothesis. Figure 3 presents estimates of RD for health outcomes. Focusing on the IPTW estimates, Panel A shows that the prevalence of asthma among children exposed to family instability is higher than among children in stable families at the one year old follow-up; but higher prevalence is smaller in magnitude among three-year-olds and even invert and turn lower among exposed five-year-old children than unexposed children. Among these older children, estimated RD indicate that children experiencing familiy instability are less likely of being diagnosed with asthma. Regarding overweight or obesity, as shown in Panel $\mathrm{B}$, the story is similar. Among children of three and nine years old exposed to changes in family structure there is a higher prevalence of obesity or overweight; whereas among five and fifteen-year-olds the RD are positive, indicating a smaller prevalence among exposed children than those who were unexposed to family instability. Regarding the probability 
of having ever tried drugs, alcohol or tobacco by age fifteen, as shown in Panel C, RD are positive, so that exposure to family instabiltiy may have had a positive effect on the chances of children enganging in unhealthy behaviors. The difference between unadjusted, adjusted by baseline confounders, and the doubly robust IPTW are small, just as the effect sizes for all health outcomes are (which in most cases do not reach statistical significance). This suggest that regarding health outcomes as a measure of well-being, the FIH is not supported by the data, and the selection hypothesis does not explain away the small effects of family structure for health behavior when children are fifteen years old.

\section{Behavioral or non-cognitive outcomes}

The findings are different for the behavioral and non-cognitive outcomes. Figure 4 shows standardized estimated coefficients for temperament in Panel A, for externalizing and in-

ternalizing problems in Panel B, and behavior at school in Panel C, all based on scales of sum of rating items; and risk differences for the event of being suspended or expelled from school. Again, considering the IPTW adjusted estimates, changes in family structure are associated negatively with all outcomes in this domain of well-being, with the sole exception of CBCL when children are three years old for which exposure to changes in family structure are associated with lower scores on the externalizing and internalizing problematic behavior scales. In comparison with the unadjusted estimates, the negative effects are substantially reduced once adjusted for baseline confounders; and reduced furthermore once adjustment for exposure-confounder feedback bias is included. For CBCL the data suggests that negative effects are larger for family transitions which occur when children are older. And the estimated RD for the event of being suspended or expelled from school, as well as the higher scores in the trouble at school scale, lend credence to the negative effect story among teenagers. In the behavioral domain, with only one exception, data does seem to support the FIH, but it also suggest that selection bias drives a large share of these negative associations. However, effects on this domain are also small. They range from -0.08 and 
up to 0.16 of a standard deviation on the scales. This corresponds well to the literature finding overall small effect sizes on this domain of children's well-being. Moreover, only the effects on the chances of being suspended or expelled from school among fifteen-year-olds are statistically significant, whereas for the rest, assuming there is no effect in the population, the data does not present enough evidence to reject the hypothesis of no effect of changes in family structure.

\section{Educational and cognitive outcomes}

Finally, Figure 5 shows results for the educational and cognitive outcomes. Panel A presents standardized estimated regression coefficients for the PPVT standardized score and the trouble at school scale. Panels $\mathrm{B}$ and $\mathrm{C}$ present RD for the events of low grades in the four subjects, as well as for ever failing a class. Changes in family structure are associated with higher cognitive ability among three-year-old children, but with lower cognitive abiliy among five and nine-year-olds with respect to children who did not experienced family transitions in the previous years. When children are fifteen years old exposure to changes in family structure are also associated with worse grades in the subjects of English, mathematics, history and science; and more chances of having ever failed a class in school, than their peers whose families did not experienced recent changes in structure. As for the other two domains, these negative effects are considerably small. They range from 0.04 and up to 0.12 percentage points for the schooling outcomes, but they remain statistically significant. The data however does not suggest an effect on the cognitive domain, in consonance with previous findings in this literature.

\section{How big are these effects?}

Finally, for a subset of these child well-being indicators, Figure 6 compares the size of the effect of unstable families to those of other three important socioeconomic characteristics that 
previous research has shown to be relevant for children's well-being (see Bernardi, Chakhaia, and Leopold (2017) and McShane et al. (2019)). The effects of having a mother with college or graduate degrees, or the effect of having a non-hispanic, black mother, or the effects of having had a mother who reported having drank, smoked or taken drugs during pregnancy, are larger than the largest effect of family instability. From Figure 6 it is clear that the weight of the socioeconomic gradient and health practices are noticeably larger than the weight of the effect of family transitions. Equivalent patterns are observed for all other outcomes, but results are not shown here due to space limitations.

\section{Discussion and Conclusions}

Using data from FFCWS, this paper contributes to the debate around the effects of changes in family structure in the U.S. in mainly three ways. First and foremost, the estimates of the causal effect of family instability, considered as a time-varying exposure, on a rich set of outcomes related to child well-being do not in general support the FIH; these estimates differ in terms of their direction and size from the unadjusted or from those that only consider baseline confounder adjustment, and most of the negative results found are small and not statistically significant, under the assumption that the effect in the population is zero.

Second, the paper agrees with critics of the FIH. Effect sizes are reduced once selection into unstable family structures is accounted for. The consistency of this finding for the various children's well-being measures suggests that other processes must be at play in the dynamics of family life; processes that probably relate to how the socioeconomic factors shape family dynamics, and not the other way around.

Third, this paper has made clear that unless researchers have directly addressed the problem of exposure-confounder feedback bias, by for example using one of the approaches from the G-methods toolbox (Mansournia et al. (2017)), most of the previous estimates of effects of family structure are merely statistical associations that remain confounded (i.e. prior 
estimates of negative effects may be explained by other factors different to demographic behavior, because such behavior is endogenous).

The remaining balance after this episode of the "War of the Titans" between the FIH and selection hypothesis crews, is the following. Considering the direction of the IPTW estimates for the twenty-six outcomes related to children's well-being, in twenty out of twenty-six, i.e. in around three quarters of them, there are negative effects of exposure to family instability; which implies that in six out of twenty-six outcomes there were positive effects of changes in family structure. However, only seven of those twenty negative effects, i.e. a third of them, were statistically significant under the assumption of no effects in the population; whereas only three out of the six positive effects, i.e. half of them, were statistically significant. So the score stands as seven statistically significant negative effects against three positive effects of exposure to family transitions. However this accounting of statistically significant effects says little about the dynamics captured by this analysis.

In summary, this re-examination of the family instability hypothesis suggests that changes in family structure are not negatively affecting the cognitive development of children; nor their general behavioral or non-cognitive development; and certainly not their health well-being. It was only when children in this cohort reached the age of fifteen years old that negative effects were found on a small set of outcomes. These statistically significant negative effects suggest, in contrast to the selection hypothesis, that children exposed to family instability are slightly negatively affected by it, net of the dynamic confounding and exposure-confounder feedback effects which are present in this association.

But is worth reminding that all effect sizes are notoriously small; that selection on unobserved confounders, such as wealth and neighborhoods is dynamic, not just static, and was not accounted for in this paper (it has not been accounted for by any other paper); and that the negative effects are potentially the result of family trajectories that are fifteen years long for which is hard to control for, especially when, as it was the case of the FFCWS, there 
were six years between the fifth and the sixth follow-up survey. This entails that exposureconfounder feedback may be harder to adjust for than previously thought especially among teenagers, and was only partially adjusted for in this paper. Therefore, lack of balance on time-varying covariates and the likely selection on theoretically relevant unobservables hampers the interpretation of these negative effects as casual. For example, given that balance in time-varying confounders could still be improved, ${ }^{12}$ there is room for those seven statistically significant negative effects to be further reduced in size and probably turn of less substantive significant, and probably not statistically significant anymore. I conjecture that once researchers find better ways to account for the complex relations between the socioeconomic conditions and family dynamics in longitudinal data, there will be no negative effects associated to exposure to family transitions left.

Results of this paper suggest in any case that the FIH should narrow down its explanatory scope to the teenage years, when making claims about children's well-being under changing family dynamics, given that no negative effects, and even a few positive ones, were found when children were in their early childhood. Moreover, one wonders to what extent, the slightly higher chances among fifteen-year-olds exposed to family transitions of getting low grades in school; or of failing a class; or of having trouble at school; or even of trying alcohol, tobacco or drugs; can be said to determine their status attainment as adults, beyond socioeconomic inequalities. It seems there is little room to assume that the destinies of children growing up in AFS, or exposed to changes in family structure, would diverge from those of children growing up in stable two-parent nuclear families. The claims of McLanahan (2004) and more recently Bloome (2017), regarding the effects of the second demographic transition on social inequality, seem therefore unwarranted by these results. My findings differ from the previous literature supporting the FIH in that a proper causal account of the dynamics of family life is explicitely considered. For this more compelling interpretation of the FIH, the findings do not favour claims of diverging destinies as result from different

\footnotetext{
${ }^{12}$ If only it were possible to arrive a better propensity score models that predict transitions in family structure over long periods of time.
} 
family structure trajectories. The tendency of estimates to reduce in size as appropriate adjustment is taken into account, suggest that to a large extent, the effects of changes in family structures can be attributed to differences in the background characteristics of mothers and fathers prior to the exposure of children to family instability.

Overall, the empirical evidence of this paper does not fit the FIH story. Partly, these results undermine the conservative trope in which AFS are seen as contributors to increases in poverty and inequality in the U.S. But they allow us to infer that promoting marriage and family/couple therapy as a means to safe-guard children from the negative effects of changes in family structure (such as the healthy marriage initiative) would have if anything a small effect on reducing poverty and inequality. Such public policies in the U.S. are clearly barking up the wrong tree (Fisher (2005)). To claim that AFS are yet another path through which inequality and poverty are transmitted from one generation to the next seems implaussible, unless it can be argued that small negative effects can have such large societal consequences. Researchers need to openly acknowledge that the empirical stylized fact that children in AFS fare worse than children in traditional marriage-based two-parent families, to which they so obssesively cling to, is based on a spurious correlation; and that furthermore it does not correspond to the realities of contemporary family life in a context of rising inequality, such as the U.S. (e.g. Lareau (2011) shows how unequal childhoods are brought about by unequal socioeconomic conditions of parents). Other studies have found that instead, lack of access to health-care and child-care, poorly funded educational institutions and lack of opportunities for education of single-mothers, and job opportunities that are compatible with family life, as well as lack of affordable housing are far more important drivers of poverty and inequality in the U.S. and far more detrimental factors negatively affecting the well-being of children, especially those from racial/ethnic minority backgrounds living in deprived urban areas.

Much stronger social forces are at play in the reproduction of social inequality. Research which zooms into the intricancies of family life has lost sight of the little substantive sig- 
nificance that changes in family structure have on children's well-being overall. Although good theoretical reasons to expect negative effects exists, a more elaborate examination of the dynamics of family life reveal nuances and complexities which haven't been accounted for so far. For example, the positive effects of family transitions in the health domain and cognitive development during early childhood may have resulted from mothers' strategies aimed at bringing new resources to the family; or from their prioritizing their children's well-being, instead of problematic previous relationships. This would go in line with what other research has found. It seems that, for example, in Finnland, fathers' contribution to the socioeconomic attainment chances of their offspring can be entirely replaced by stepfathers or the strenghtening compensating role of the mother (Erola and Jalovaara (2017)). But is certainly not compatible with the FIH.

Moverover, and in open opposition to the FIH, whereby the roles of the father and the mother are "fixed" entities required for appropriate child development, cross-cultural and contemporary anthropological studies of American families find that individuals in AFS build their own narratives around what is required, necessary or important for children and parenting (Levine (2008), Bengtson (2001)). Research on family dynamics should reconsider how the experiences of people in AFS are shaped by their environments. This would be much closer to ethnographic accounts of the interactions between socioeconomic conditions and family life as perceived by individuals themselves (e.g. Jarrett (1994)).

The life-course of children who experience changes, even repeated changes, in family structure tell a more complex story than previous accounts have told researchers about. More sound understandings of family dynamics ought to make room for people's agency in their choices of family life, as informed by the structural constraints in which they try to navigate the demands of work and family (Damaske, Bratter, and Frech (2017)); as well as considering potential alternative sources of strength and resilience which AFS also possess (Orthner, Jones-Sanpei, and Williamson (2003)). 
This paper is therefore a call for researchers to refocus on how children's well-being heavily depends on the weight of the socioeconomic gradient and not on hypothesized harmful psychological effects of dysfunctional families or absent relationship figures in children's lives. Furthermore, behind the FIH lie hidden several pressupositions of the family discourse. Anthropological or historical cross-cultural studies of family life, as discussed in Bourdieu (1993), show the benefits of taking the ethnomethodological step of suspending the researcher's beliefs in the categories dictated by the family discourse, such as the family as a decision unit, family as private, as in concerning only their members' interactions, and as durable or stable unit in time (e.g. the family name, the family home). The family discourse, as portrayed in the writings of sociologists and demographers, ignores that these pressupositions are largely the result of social conditions. Instead of the disproportionate weight given to psychological explanations of family dynamics, research on the effects of family structure should refocus their efforts in understanding how having children in stable marriage-based two-parent households is something that only people in certain social conditions are enabled to do, and willingly do in order to comply to prevalent notions of the ideal family life (as the selection hypothesis suggests). Others, whose socioeconomic conditions prevent them from abide to this discourse, seek to build families in alternative ways nonetheless (Nieuwenhuis and Maldonado (2018)); families that suit their contexts amid the adversities with which they are faced.

Furthermore, sociological understandings of family dynamics should continue to further theorize and empirically assess the role played by the State in the configuration of family structures and their different living standards (e.g. Pilkauskas and Michelmore (2019) and Maldonado and Nieuwenhuis (2015)). For example, housing/dwelling urban planning policies to develop suburbs or gated communities for middle class families, strongly contrast with the construction of large urban housing projects for low income families. Both of these policies contribute to the creation of social spaces of different kinds and in which diverging familiy dynamics will unfold over time, as they are affected by residential context effects 
(see Sharkey and Faber (2014) for residential context effects on children). Morever, tax and social welfare policies that benefit or harm individuals in certain social positions (Edin and Kissane (2010)), also affect the configuration of certain family forms. By supposedly merely describing how family structure relates to measures of children's well-being, researchers remain ignorant of how a particular historical reality of family formation comes to be, at least partially, as a result of structural forces ordained by the State. If family as a social category contributes to the reproduction of social inequalities it does so only to the extent that individuals perceive the social world through this particular social category of the nuclear family; and engage in actions and strategies that seek to reproduce nuclear families through institutional sanctioned rituals which guarantee the transmission of different forms of capital within one's own imagined kin; while keeping away from such ideals other individuals whom by law (e.g. as it was the case of same-sex marriage) or by their socioeconomic circumstances (see Lauster (2010) and Edin and Kissane (2010)) lack the means to keep up with the expectations of the American family life.

Limitations Some limitations regarding the empirical findings follow. First, the probability that the estimates here presented are still upwardly biased should be considered, given selection on unobservables. These may reduce the already small effect sizes found for those seven outcomes. Wealth remains the least studied socioeconomic dimension that may drive the selection of couples into marriage and stable family trajectories, but others such as sociooccupational attaintment or neighborhood effects can have similar effects. The FFCWS did not include any measure on the wealth of parents, nor of their specific socio-occupational class, though some information on neighborhoods may be available through restricted user agreements. Future research should address this.

Second, measurement error may induce further bias in the association between family instability and children's well-being, which was not considered in this paper. For example, psychological well-being variables, such as cognitive or noncognitive skills, are unobserved 
constructs which are measured with error. In basic causal effect notation $Y_{t}$ is the score on some standardized assessment or rating, which is a function $f$ of $Y_{t}^{*}$ which is the "true" though unobserved trait, and $U^{Y}$ which is an error term (as in $Y_{t}=f\left(Y_{t}^{*}, U^{Y}\right)$ ). Regarding this last error term, researchers usually assume that is random or exogenous (i.e. classical measurement error). Of special concern in this regard are the scales built from maternal ratings. Family transitions may make some mothers more keen observers of their child's behavior than others. For example, the time at work, or certain characteristics of their neighborhood or housing may affect the accuracy with which they notice, remember and report on some specific behavioral aspect of their children; or affect their opportunities to observe their child's behavior, therefore biasing the response to items in non random ways. Some evidence supports this claim, in the sense that lone-mothers or full-time working mothers, who for example live in housing projects are less able to supervise children than stay-athome married or cohabiting mothers who only work part-time. In this way family structure affects the error term and artificially creates a statistical association between changes in family structure and the score obtained by summing up items in a ratings checklist. Yet so far the literature has not discussed this in relation to the estimation of family structure effects on the behavioral or non-cognitive domain. It must be said though that there is little that can be done to address this issue with current statistical tools, under not so restrictive assumptions, besides trying to device better measurement instruments.

Conclusion The paper has discussed the notion of family instability or its fragility by looking at the processes that affect both the changes in family structures and children's well-being. By doing so, the paper echoes calls of researchers to reconsider the "fragile families" discourse (Hadfield, Ungar, and Nixon (2018)), and improve upon the working definition of family in demographic research (Seltzer (2019)) in an attempt at better capturing contemporary dynamics of family life. I suggest researchers can do this by tying together anthropological studies of families in contemporary U.S. with traditional demographic defi- 
nitions of a household.

Researchers ought to be aware of the role of family privilege in family theory and research as suggested by Hadfield, Ungar, and Nixon (2018). Conceiving the marriage-base, two-parent family as the benchmark to which other family forms ought to be compared to, reminds us of the ethnocentric perspective of White middle-class researchers who insist that children "fare better" under — demographically speaking - living arrangements most similar to their own; meanwhile unconvincingly showing biased estimates of family structure effects in support of such claims.

Finally, most research has not properly addressed the reflection problem in the identification of causal effects of family transitions on children's well-being. This paper has shown, as past research had discussed (Manski (1993); or Ginther and Pollak (2004, 691-93) for family behavior), that the stylized fact which forms the basis of the FIH is ill-founded (Hirschman (2016)). It seems instead that the data does not support the claim of substantial negative effects on children after being exposed to alternative family structures or family transitions, not even in a large study which was specifically designed to support that hypothesis.

Acknoledgments This paper was presented at the Final Event of the Demography and Inequality Workshop in Berlin. There it benefited from the comments and suggestions of Raffaella Piccarretta and Juho Härkonen. Special thanks to Anette Fasang and Jascha Dräger for valuable feedback on a previous version of the manuscript. 


\section{Tables}

Table 1: Descriptive Statistics for Analytical Variables in the FFCWS Initial Sample by Family Structure at Birth

\begin{tabular}{|c|c|c|c|c|c|c|}
\hline & & $\begin{array}{l}\text { Married or } \\
\text { Cohabiting } \\
\text { two parents }\end{array}$ & Lone-parent & $\begin{array}{l}\text { Complex, } \\
\text { step or } \\
\text { blended } \\
\text { family }\end{array}$ & LAT & Missing \\
\hline $\mathrm{N}$ & Count & 1979 & 1286 & 28 & 148 & 1 \\
\hline Mother's age & Median & 25 & 22 & 23.5 & 25 & 22 \\
\hline Father's age & Median & 28 & 24 & 26 & 27 & - \\
\hline \multirow[t]{5}{*}{ Mother's race $(\%)$} & White, non-hispanic & 32.4 & 12.9 & 28.6 & 19.6 & 0 \\
\hline & Black, non-hispanic & 30.2 & 58.5 & 57.1 & 43.9 & 0 \\
\hline & Hispanic & 32.1 & 25.7 & 14.3 & 33.8 & 100 \\
\hline & Other & 5.1 & 3 & 0 & 2.7 & 0 \\
\hline & Missing & 0.2 & 0 & 0 & 0 & 0 \\
\hline \multirow[t]{5}{*}{ Father's race (\%) } & White, non-hispanic & 30.2 & 8.9 & 10.7 & 15.5 & 0 \\
\hline & Black, non-hispanic & 31.7 & 61.4 & 57.1 & 43.9 & 0 \\
\hline & Hispanic & 32.8 & 24.8 & 21.4 & 34.5 & 100 \\
\hline & Other & 5.3 & 3.2 & 7.1 & 6.1 & 0 \\
\hline & Missing & 0.1 & 1.7 & 3.6 & 0 & 0 \\
\hline \multirow{3}{*}{$\begin{array}{l}\text { Mother born in U.S. } \\
(\%)\end{array}$} & No & 19.6 & 10.7 & 3.6 & 26.4 & 0 \\
\hline & Yes & 80.3 & 89 & 96.4 & 73.6 & 100 \\
\hline & Missing & 0.1 & 0.3 & 0 & 0 & 0 \\
\hline \multirow{3}{*}{$\begin{array}{l}\text { Father born in U.S. } \\
(\%)\end{array}$} & No & 18.2 & 5.2 & 3.6 & 22.3 & 0 \\
\hline & Yes & 73.1 & 55.8 & 57.1 & 52 & 0 \\
\hline & Missing & 8.6 & 39 & 39.3 & 25.7 & 100 \\
\hline \multirow[t]{3}{*}{$\begin{array}{l}\text { Mother's religiosity } \\
(\%)\end{array}$} & Seldom or never & 39.8 & 43.2 & 21.4 & 30.4 & 100 \\
\hline & At least once a year & 60.2 & 56.6 & 78.6 & 68.2 & 0 \\
\hline & Missing & 0.1 & 0.2 & 0 & 1.4 & 0 \\
\hline \multirow[t]{3}{*}{ Father's religiosity (\%) } & Seldom or never & 40.9 & 30.1 & 28.6 & 29.1 & 0 \\
\hline & At least once a year & 50.5 & 30.9 & 32.1 & 45.3 & 0 \\
\hline & Missing & 8.6 & 39 & 39.3 & 25.7 & 100 \\
\hline
\end{tabular}


Table 1: Descriptive Statistics for Analytical Variables in the FFCWS Initial Sample by Family Structure at Birth (continued)

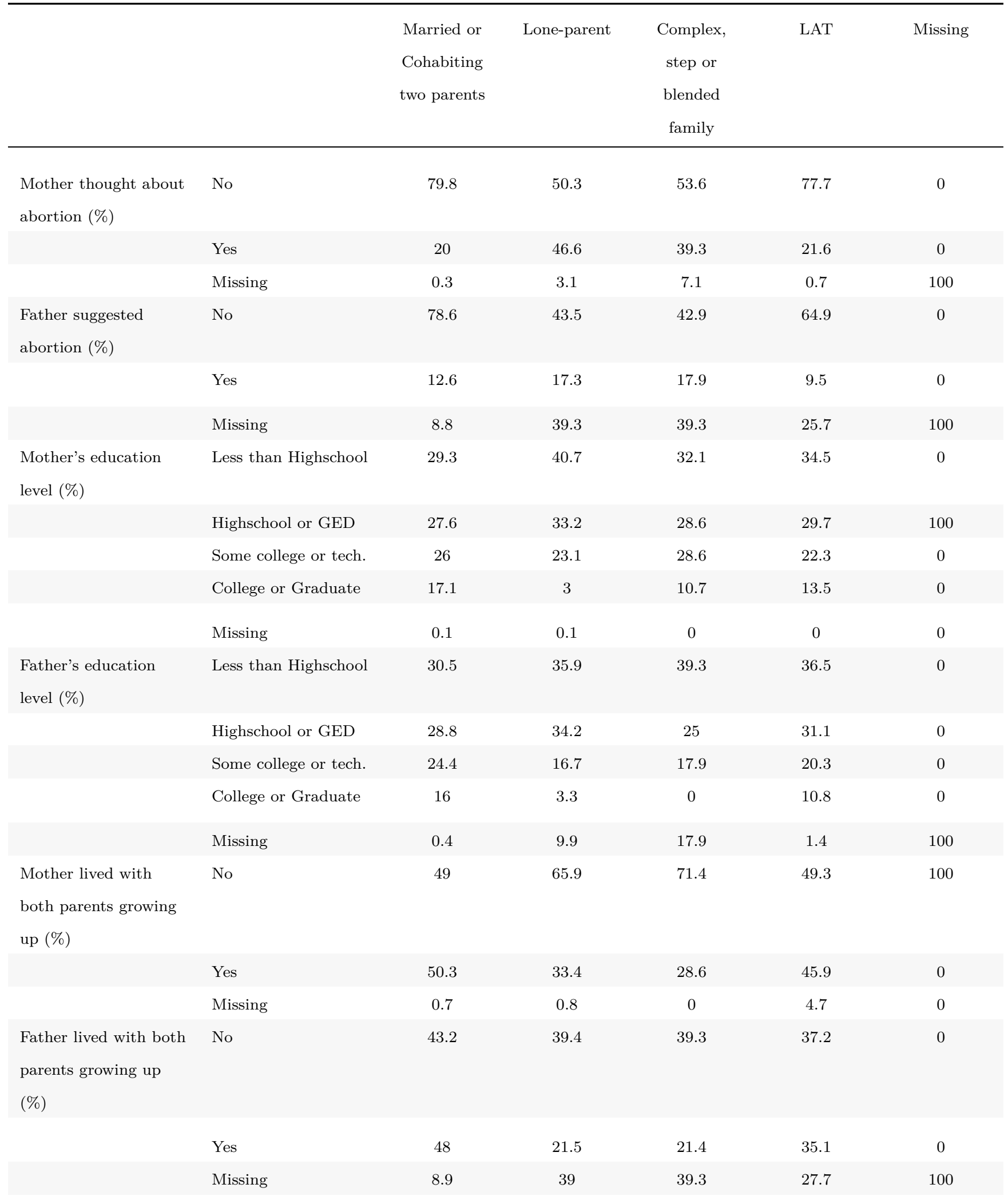


Table 1: Descriptive Statistics for Analytical Variables in the FFCWS Initial Sample by Family Structure at Birth (continued)

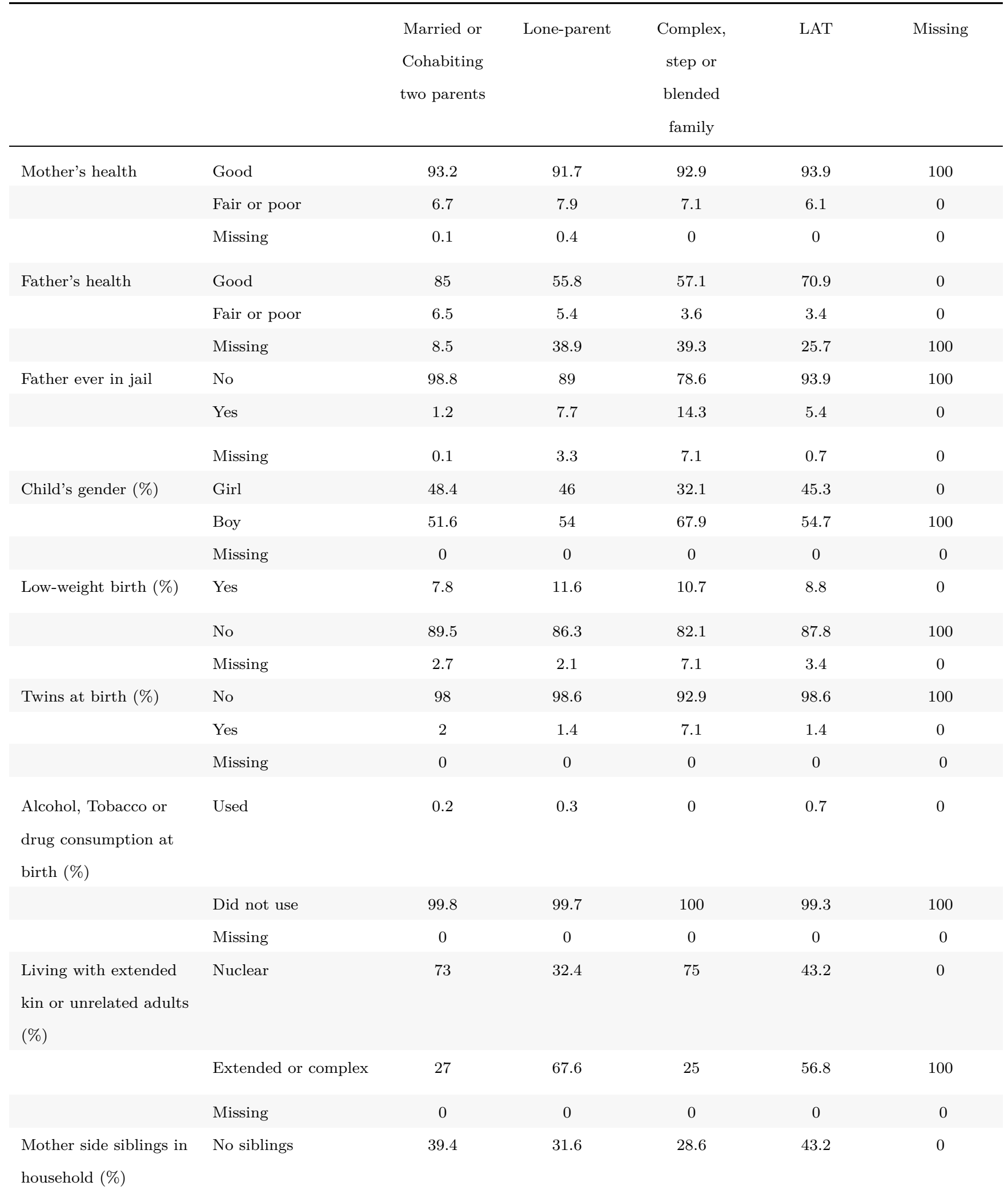


Table 1: Descriptive Statistics for Analytical Variables in the FFCWS Initial Sample by Family Structure at Birth (continued)

\begin{tabular}{|c|c|c|c|c|c|c|}
\hline & & $\begin{array}{l}\text { Married or } \\
\text { Cohabiting } \\
\text { two parents }\end{array}$ & Lone-parent & $\begin{array}{l}\text { Complex, } \\
\text { step or } \\
\text { blended } \\
\text { family }\end{array}$ & LAT & Missing \\
\hline & Siblings present & 60.6 & 68.4 & 71.4 & 56.8 & 100 \\
\hline & Missing & 0 & 0 & 0 & 0 & 0 \\
\hline \multirow{3}{*}{$\begin{array}{l}\text { Violence by partner } \\
\text { against mother (\%) }\end{array}$} & No & 68.7 & 81.4 & 39.3 & 66.9 & 100 \\
\hline & Yes & 26.2 & 18.6 & 7.1 & 33.1 & 0 \\
\hline & Missing & 5.2 & 0 & 53.6 & 0 & 0 \\
\hline \multirow{3}{*}{$\begin{array}{l}\text { Mother does paid } \\
\text { work (\%) }\end{array}$} & No & 41.2 & 41.3 & 53.6 & 50 & 0 \\
\hline & Yes & 48.7 & 47.6 & 39.3 & 37.2 & 0 \\
\hline & Missing & 10.1 & 11.1 & 7.1 & 12.8 & 100 \\
\hline \multirow[t]{3}{*}{ Changed home (\%) } & Did not moved & 43.9 & 52 & 42.9 & 48 & 0 \\
\hline & Moved & 33.1 & 25 & 42.9 & 29.1 & 100 \\
\hline & Missing & 23 & 23 & 14.3 & 23 & 0 \\
\hline \multirow[t]{3}{*}{ Lives on rent (\%) } & Own house & 36.8 & 35.1 & 21.4 & 33.1 & 0 \\
\hline & Renting & 62.5 & 64 & 78.6 & 64.9 & 100 \\
\hline & Missing & 0.7 & 0.9 & 0 & 2 & 0 \\
\hline \multirow{6}{*}{$\begin{array}{l}\text { Income to poverty rate } \\
\text { categories }\end{array}$} & $0-49 \%$ & 12.7 & 27.8 & 32.1 & 19.6 & 100 \\
\hline & $50-99 \%$ & 12.3 & 20 & 10.7 & 19.6 & 0 \\
\hline & $100-199 \%$ & 24.2 & 28.2 & 25 & 24.3 & 0 \\
\hline & $200-299 \%$ & 17.4 & 14.4 & 10.7 & 13.5 & 0 \\
\hline & $300 \%$ & 33.4 & 9.6 & 21.4 & 23 & 0 \\
\hline & Missing & 0 & 0 & 0 & 0 & 0 \\
\hline $\begin{array}{l}\text { Nominal equivalized } \\
\text { household income }\end{array}$ & Median & 15910 & 8839 & 9856 & 11599 & 3750 \\
\hline $\begin{array}{l}\text { Mother'S cognitive } \\
\text { skills (PPVT std. } \\
\text { score) }\end{array}$ & Median & 93 & 87 & 85 & 85 & - \\
\hline
\end{tabular}

Note:

Unweighted Sample. Mother's employment is measured one year after birth 
Table 2: Relative Risks for Time-varying Confounders as Predictors of Changes in Family structure at each Follow-up

\begin{tabular}{|c|c|c|c|c|}
\hline Change in family structure at $\mathrm{t}$ & Time-varying confounders at t- 1 & Estimate & Low & High \\
\hline \multirow[t]{9}{*}{ Birth and 1st year } & Income to Poverty: $50-99 \%$ & 0.96 & 0.89 & 1.04 \\
\hline & Income to Poverty: $100-199 \%$ & 1.07 & 1.00 & 1.14 \\
\hline & Income to Poverty: $200-299 \%$ & 0.98 & 0.87 & 1.10 \\
\hline & Income to Poverty: $300 \%$ & 0.95 & 0.87 & 1.04 \\
\hline & Living with extended kin or unrelated adults & 1.00 & 0.95 & 1.05 \\
\hline & Lives on rent & 1.04 & 1.00 & 1.09 \\
\hline & Change in residence & 1.02 & 0.96 & 1.10 \\
\hline & Mother-side siblings in household & 1.03 & 0.99 & 1.06 \\
\hline & Violence by partner against mother & 1.00 & 0.95 & 1.04 \\
\hline \multirow[t]{10}{*}{ 1st year through 3 rd year } & Income to Poverty: $50-99 \%$ & 0.96 & 0.65 & 1.43 \\
\hline & Income to Poverty: 100-199\% & 0.81 & 0.54 & 1.21 \\
\hline & Income to Poverty: 200-299\% & 0.70 & 0.38 & 1.29 \\
\hline & Income to Poverty: $300 \%$ & 0.76 & 0.38 & 1.51 \\
\hline & Living with extended kin or unrelated adults & 1.15 & 0.88 & 1.51 \\
\hline & Lives on rent & 1.29 & 0.70 & 2.38 \\
\hline & Change in residence & 1.12 & 0.83 & 1.51 \\
\hline & Mother-side siblings in household & 0.77 & 0.41 & 1.44 \\
\hline & Violence by partner against mother & 1.29 & 0.90 & 1.86 \\
\hline & Mother does paid work & 1.15 & 0.84 & 1.56 \\
\hline \multirow[t]{10}{*}{3 rd year through 5 th year } & Income to Poverty: 50-99\% & 0.88 & 0.54 & 1.42 \\
\hline & Income to Poverty: $100-199 \%$ & 0.73 & 0.48 & 1.10 \\
\hline & Income to Poverty: $200-299 \%$ & 0.99 & 0.55 & 1.80 \\
\hline & Income to Poverty: $300 \%$ & 0.71 & 0.38 & 1.33 \\
\hline & Living with extended kin or unrelated adults & 1.24 & 0.87 & 1.77 \\
\hline & Lives on rent & 1.41 & 0.79 & 2.51 \\
\hline & Change in residence & 0.93 & 0.65 & 1.34 \\
\hline & Mother-side siblings in household & 0.91 & 0.53 & 1.54 \\
\hline & Violence by partner against mother & 1.54 & 1.20 & 1.99 \\
\hline & Mother does paid work & 1.10 & 0.81 & 1.50 \\
\hline \multirow[t]{3}{*}{5 th year through 9 th year } & Income to Poverty: $50-99 \%$ & 1.03 & 0.66 & 1.62 \\
\hline & Income to Poverty: $100-199 \%$ & 0.91 & 0.57 & 1.46 \\
\hline & Income to Poverty: $200-299 \%$ & 1.08 & 0.48 & 2.45 \\
\hline
\end{tabular}


Table 2: Relative Risks for Time-varying Confounders as Predictors of Changes in Family structure at each Follow-up (continued)

\begin{tabular}{|c|c|c|c|c|}
\hline Change in family structure at $t$ & Time-varying confounders at t- 1 & Estimate & Low & High \\
\hline & Income to Poverty: $300 \%$ & 0.88 & 0.57 & 1.35 \\
\hline & Living with extended kin or unrelated adults & 1.01 & 0.76 & 1.36 \\
\hline & Lives on rent & 1.89 & 1.08 & 3.29 \\
\hline & Change in residence & 0.96 & 0.71 & 1.32 \\
\hline & Mother-side siblings in household & 0.54 & 0.39 & 0.75 \\
\hline & Violence by partner against mother & 1.26 & 1.01 & 1.56 \\
\hline & Mother does paid work & 1.16 & 0.80 & 1.70 \\
\hline \multirow[t]{10}{*}{9 th year through 15 th year } & Income to Poverty: $50-99 \%$ & 1.49 & 0.94 & 2.36 \\
\hline & Income to Poverty: $100-199 \%$ & 1.02 & 0.67 & 1.55 \\
\hline & Income to Poverty: $200-299 \%$ & 0.82 & 0.45 & 1.49 \\
\hline & Income to Poverty: $300 \%$ & 1.27 & 0.73 & 2.20 \\
\hline & Living with extended kin or unrelated adults & 1.33 & 0.89 & 1.99 \\
\hline & Lives on rent & 1.23 & 0.75 & 2.03 \\
\hline & Change in residence & 1.28 & 0.98 & 1.67 \\
\hline & Mother-side siblings in household & 0.74 & 0.45 & 1.21 \\
\hline & Violence by partner against mother & 1.16 & 0.84 & 1.60 \\
\hline & Mother does paid work & 1.32 & 0.95 & 1.84 \\
\hline
\end{tabular}

Note:

Weighted sample using replicate weights

Table 3: Sample Prevalence of Stable and Unstable Families at each Follow-up t by Family Structure at t-1

\begin{tabular}{|c|c|c|c|c|c|c|c|c|c|c|c|c|c|c|c|}
\hline & \multicolumn{2}{|c|}{ 2nd Wave } & \multicolumn{3}{|c|}{ 3rd Wave } & \multicolumn{3}{|c|}{ 4th Wave } & \multicolumn{3}{|c|}{ 5th Wave } & \multicolumn{3}{|c|}{ 6th Wave } & \multirow[b]{2}{*}{$\%$} \\
\hline & Stable & Unstable & $\%$ & Stable & Unstable & $\%$ & Stable & Unstable & $\%$ & Stable & Unstable & $\%$ & Stable & Unstable & \\
\hline B & 8 & 18 & 2.2 & 61 & 86 & 10.7 & 176 & 121 & 14.6 & 216 & 167 & 21.0 & 334 & 205 & 24.6 \\
\hline $\mathrm{L}$ & 6 & 123 & 14.8 & 8 & 25 & 3.1 & 7 & 74 & 8.9 & 5 & 50 & 6.3 & 1 & 41 & 4.9 \\
\hline S & 804 & 342 & 41.1 & 782 & 331 & 41.3 & 807 & 302 & 36.5 & 709 & 336 & 42.2 & 758 & 320 & 38.3 \\
\hline $\mathrm{T}$ & 1432 & 349 & 41.9 & 1321 & 359 & 44.8 & 1109 & 331 & 40.0 & 842 & 244 & 30.6 & 669 & 269 & 32.2 \\
\hline Total & 2250 & 832 & 100.0 & 2172 & 801 & 100.0 & 2099 & 828 & 100.0 & 1772 & 797 & 100.0 & 1762 & 835 & 100.0 \\
\hline
\end{tabular}




\section{Figures}

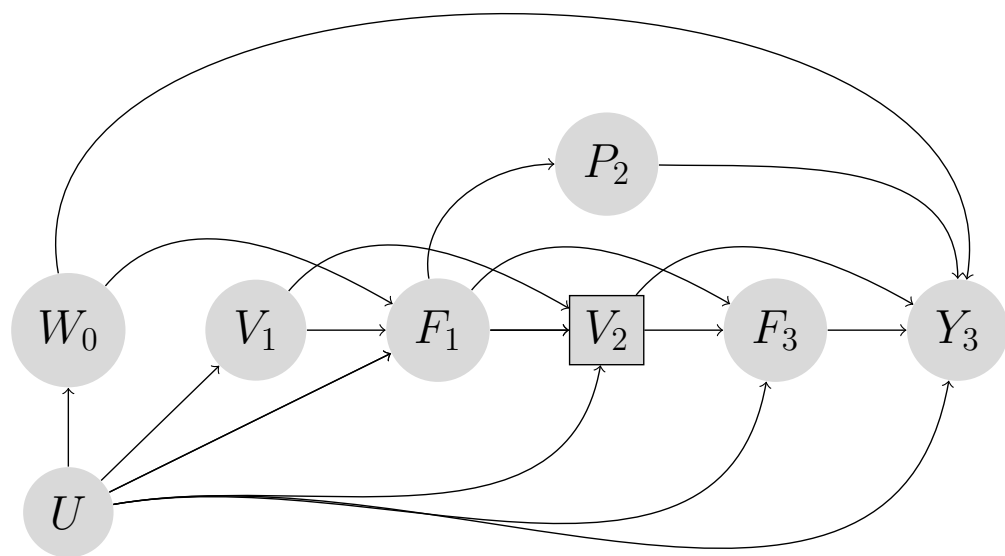

Note: Each node represents sets of analytical variables classified by their role as time-fixed confounders, time-varying confounders, exposure, mediators and outcomes; and each edge the causal hypothesized association between them.

Figure 1: Simplified DAG for the FIH and the Selection Hypotheses 
1st Wave: Newborn

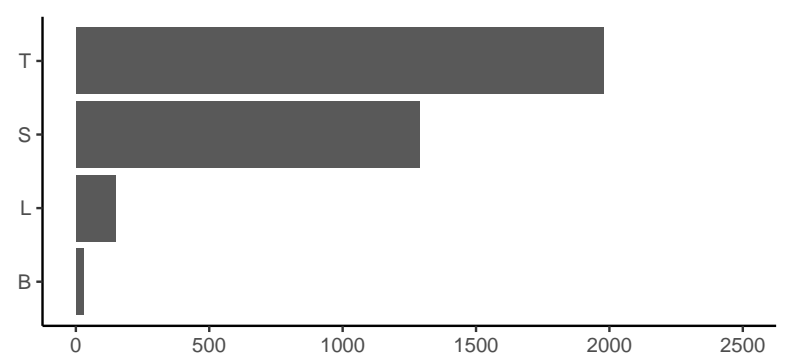

3rd Wave: Three years old

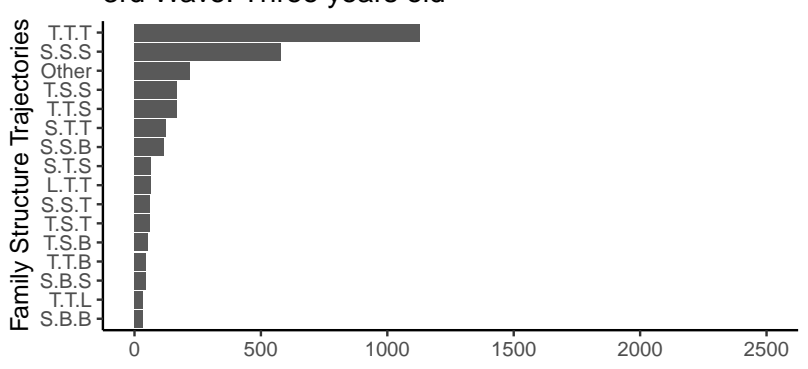

5th Wave: Nine years old

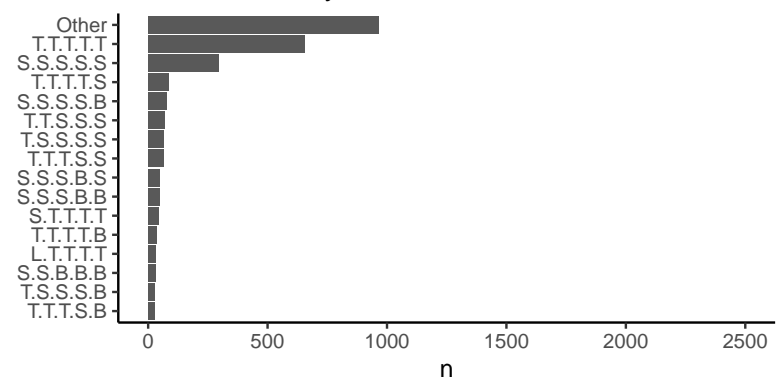

2nd Wave: One year old

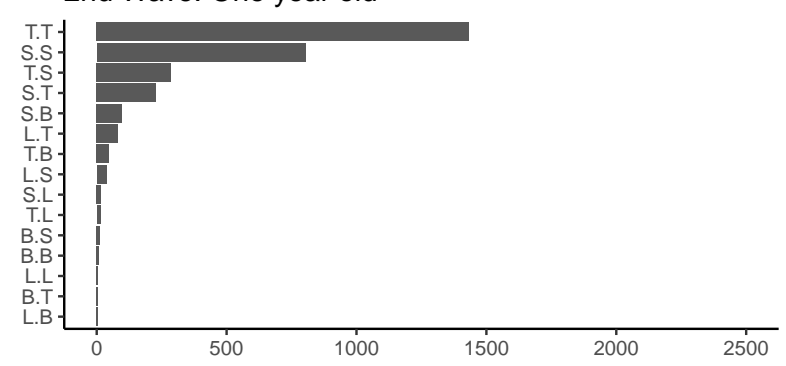

4th Wave: Five years old

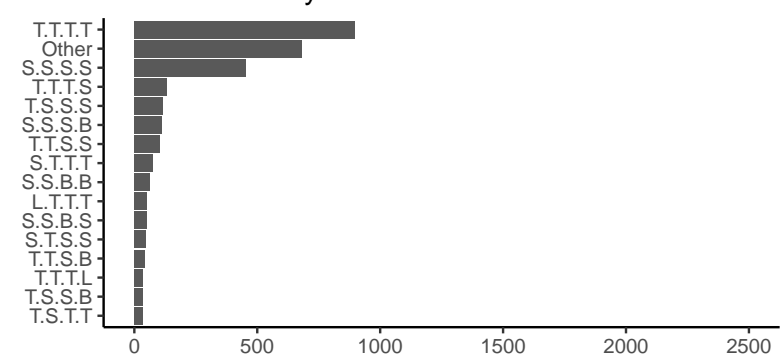

6th Wave: Fifteen years old

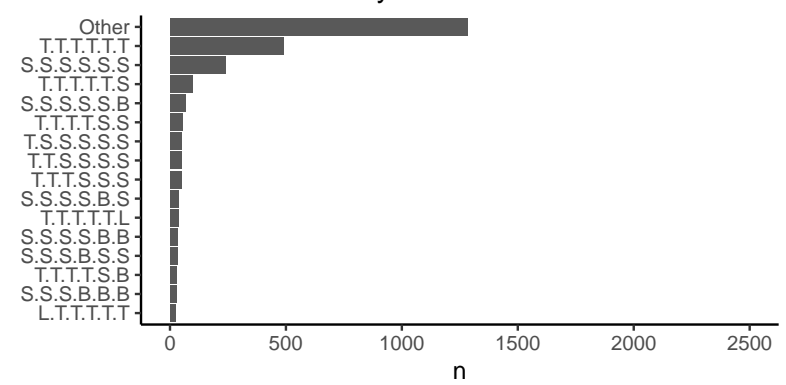

Figure 2: Frequency of Observed Trajectories of Childhood Family Structure in the FFCWS Sample at each Follow-up 


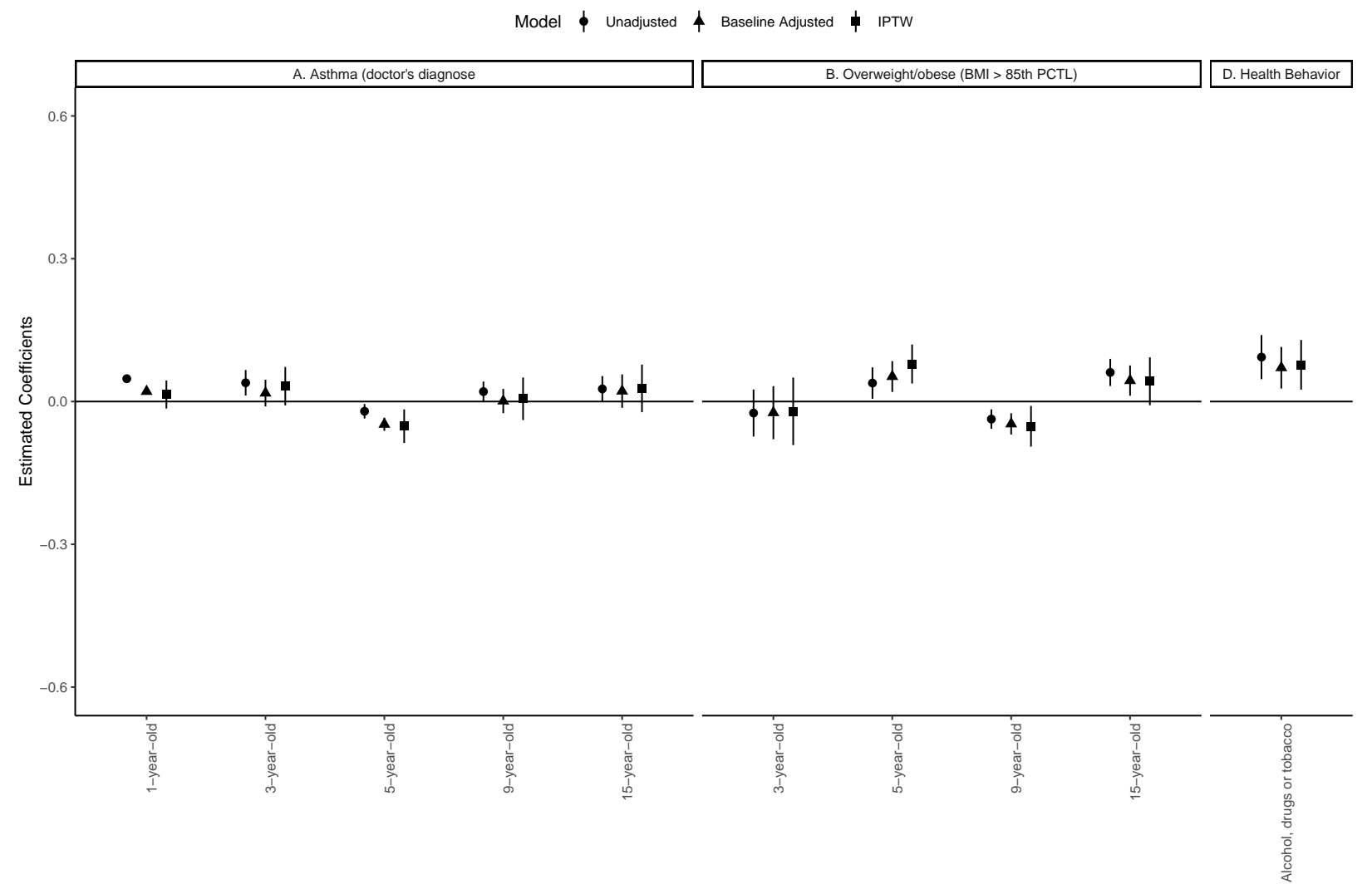

Figure 3: Sample estimates of the Effect of Changes in Family Structure on Health Outcomes in the FFCWS for Unadjusted, Baseline Confounder Adjusted, and doubly robust IPTW Models 


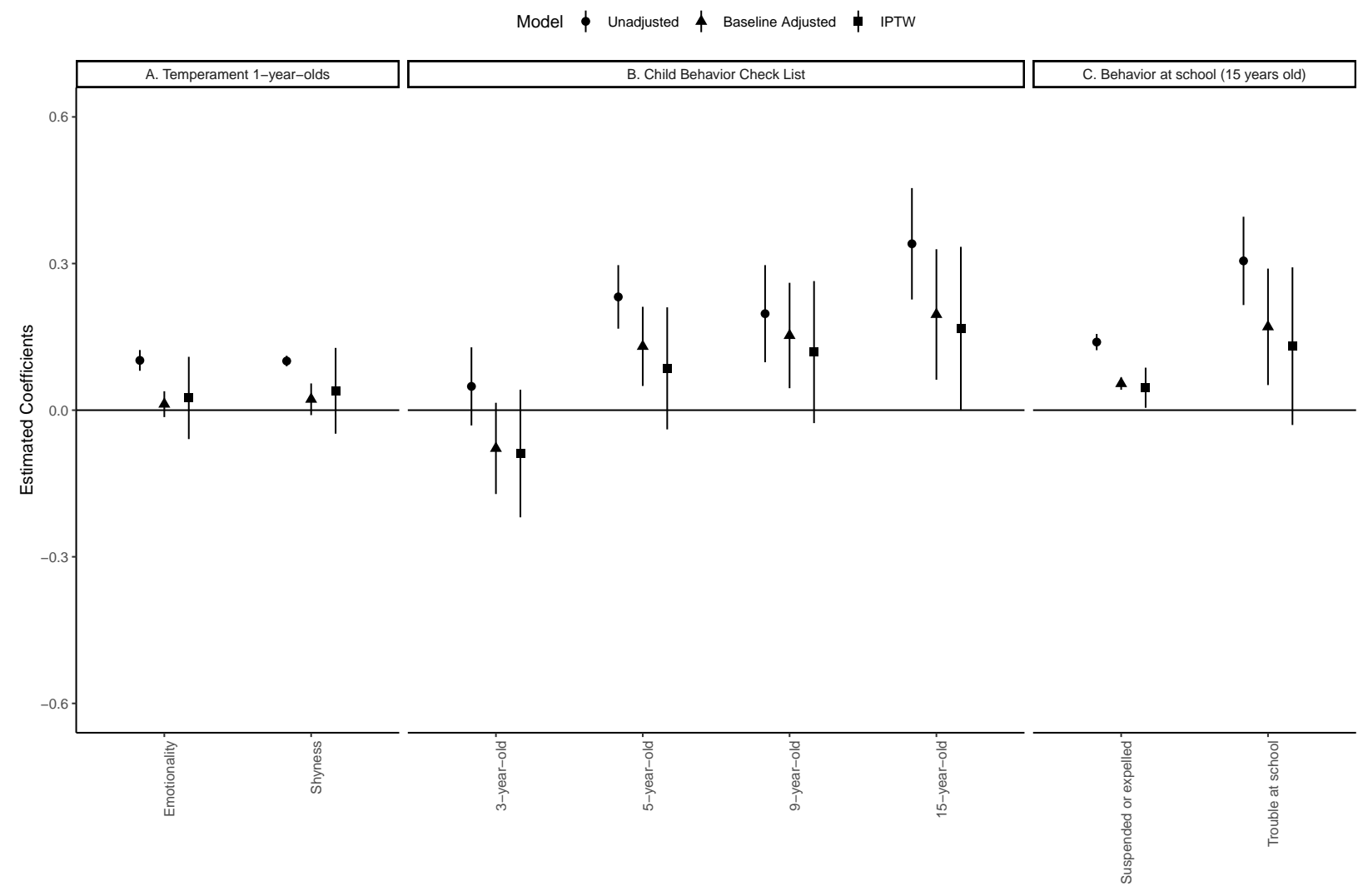

Figure 4: Sample estimates of the Effect of Changes in Family Structure on Behavioral and Non-cognitive Outcomes in the FFCWS for Unadjusted, Baseline Confounder Adjusted, and doubly robust IPTW Models 


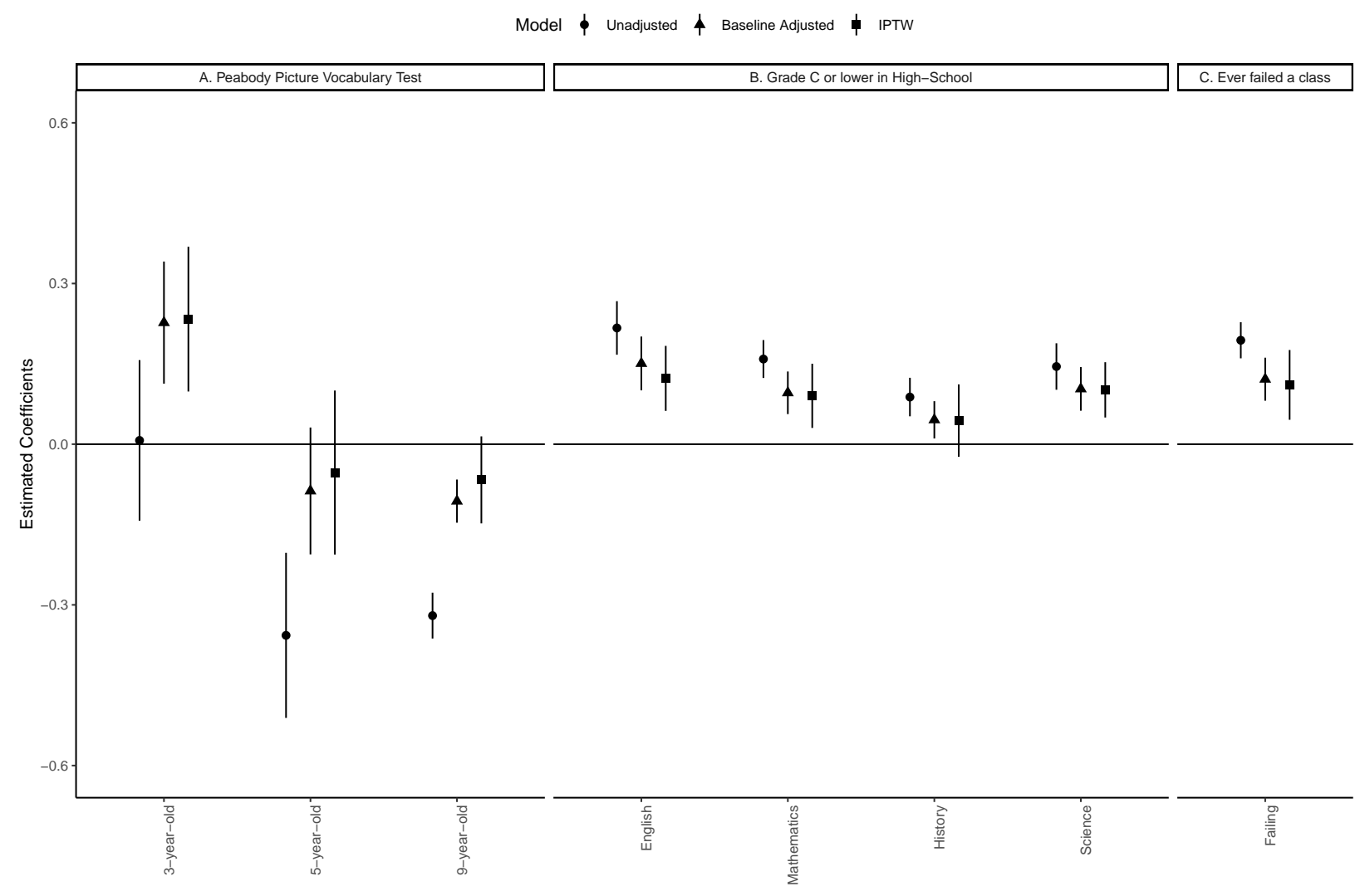

Figure 5: Sample estimates of the Effect of Changes in Family Structure on Educational and Cognitive Outcomes in the FFCWS for Unadjusted, Baseline Confounder Adjusted, and doubly robust IPTW Models 

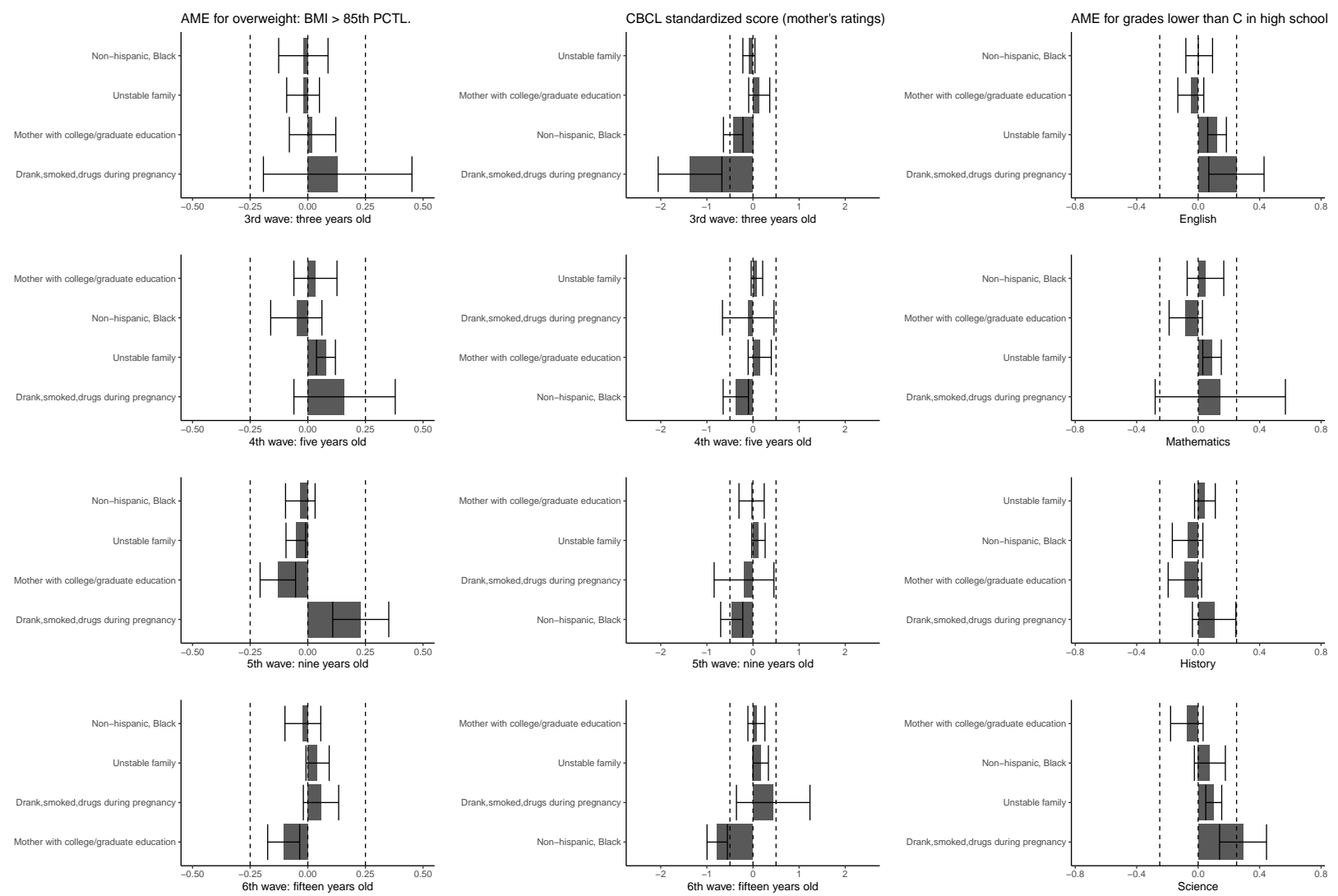

Figure 6: Comparison of Effect Sizes of Changes in Family Structure v. Other Covariates in the FFCW for a Selection of Outcomes 


\section{Supplementary material}

This section presents descriptive statistics of the computed stabilized weights and the balance achieved by re-weighting the sample. Only time-varying confounders are shown.

Summary statistics of children's well-being measures at each time-point 
Table 4: Descriptive Statistics for Well-being Outcome variables at Follow-up Times

\begin{tabular}{|c|c|c|c|c|c|c|c|c|}
\hline \multirow[b]{2}{*}{ Variables } & \multirow[b]{2}{*}{ waves } & \multicolumn{6}{|c|}{ Descriptives } & \multirow[b]{2}{*}{$\%$ cut-off } \\
\hline & & $\mathrm{N}$ & Min & Max & Mean & Median & n Cut-off & \\
\hline \multirow{5}{*}{ Asthma (doctor's diagnose) } & 2 nd & 3082 & 0 & 1 & - & - & 376 & 12.2 \\
\hline & $3 \mathrm{rd}$ & 2973 & 0 & 1 & - & - & 522 & 17.6 \\
\hline & 4 th & 2927 & 0 & 1 & - & - & 595 & 20.3 \\
\hline & 5 th & 2569 & 0 & 1 & - & - & 592 & 23.0 \\
\hline & 6 th & 2597 & 0 & 1 & - & - & 634 & 24.4 \\
\hline \multirow[t]{4}{*}{ Overweight/Obesity based on BMI } & $3 \mathrm{rd}$ & 2973 & 12.2 & 32.3 & 16.8 & 16.6 & 433 & 14.6 \\
\hline & 4 th & 2927 & 11.9 & 42 & 16.7 & 16.2 & 432 & 14.8 \\
\hline & 5 th & 2569 & 9.8 & 43.5 & 19.4 & 18.1 & 372 & 14.5 \\
\hline & 6 th & 2597 & 9.5 & 62.4 & 24 & 22.5 & 387 & 14.9 \\
\hline Substance use & 6 th & 2597 & 0 & 1 & - & - & 738 & 28.4 \\
\hline Child's Emotionality & 2 nd & 3082 & 3 & 15 & 8.4 & 8 & 1384 & 44.9 \\
\hline Child's Shyness & 2 nd & 3082 & 3 & 15 & 7 & 7 & 1204 & 39.1 \\
\hline \multirow[t]{4}{*}{ Child Behavior Problems (CBCL) } & $3 \mathrm{rd}$ & 2973 & 0 & 86 & 26.1 & 24 & 1429 & 48.1 \\
\hline & 4 th & 2927 & 0 & 68 & 16.4 & 14 & 1450 & 49.5 \\
\hline & 5 th & 2569 & 0 & 248 & 40.7 & 37 & 1224 & 47.6 \\
\hline & 6 th & 2597 & 0 & 57 & 10.5 & 8 & 1230 & 47.4 \\
\hline Suspended or expelled & 6 th & 2597 & $\mathrm{~F}$ & $\mathrm{~A}$ & - & - & 652 & 25.1 \\
\hline Trouble at School scale & 6 th & 2597 & 0 & 8 & 3.2 & 3 & 1092 & 42.0 \\
\hline \multirow[t]{3}{*}{ Peabody Picture and Vocabulary Test (PPVT) } & $3 \mathrm{rd}$ & 2973 & 40 & 137 & 86.9 & 87 & 1423 & 47.9 \\
\hline & 4 th & 2927 & 40 & 133 & 94.2 & 96 & 1448 & 49.5 \\
\hline & 5 th & 2569 & 37 & 159 & 93.6 & 93 & 1245 & 48.5 \\
\hline English grade lower than $\mathrm{C}$ & 6 th & 2597 & $\mathrm{~F}$ & $\mathrm{~A}$ & - & - & 734 & 28.3 \\
\hline Mathematics grade lower than $\mathrm{C}$ & 6 th & 2597 & $\mathrm{~F}$ & $\mathrm{~A}$ & - & - & 985 & 37.9 \\
\hline History grade lower than $\mathrm{C}$ & 6 th & 2597 & $\mathrm{~F}$ & $\mathrm{~A}$ & - & - & 868 & 33.4 \\
\hline Science grade lower than $\mathrm{C}$ & 6 th & 2597 & $\mathrm{~F}$ & $\mathrm{~A}$ & - & - & 878 & 33.8 \\
\hline Ever failed a class & 6 th & 2597 & 0 & 1 & - & - & 1241 & 47.8 \\
\hline
\end{tabular}

Note:

Unweighted Sample 


\section{Summary measures of stabilized weights across imputations}

Stabilized weights across imputations are shown in Table 5. No extreme weights were found and the mean of these weights is very close to one. The weights have good statistical properties.

Table 5: Descriptive statistics of Computed Stabilized Weights across Fifty-six Imputations

\begin{tabular}{|c|c|c|c|c|c|}
\hline Wave & Descriptives & Mean & Median & Min & $\operatorname{Max}$ \\
\hline \multirow[t]{6}{*}{ At wave 2} & Min. & 0.704 & 0.704 & 0.677 & 0.720 \\
\hline & 1st Quantile & 0.947 & 0.947 & 0.939 & 0.953 \\
\hline & Median & 0.993 & 0.993 & 0.992 & 0.996 \\
\hline & Mean & 0.998 & 0.998 & 0.997 & 0.999 \\
\hline & 3rd Quantile & 1.039 & 1.039 & 1.034 & 1.045 \\
\hline & Max. & 1.439 & 1.439 & 1.392 & 1.515 \\
\hline \multirow[t]{6}{*}{ At wave 3} & Min. & 0.634 & 0.634 & 0.592 & 0.671 \\
\hline & 1st Quantile & 0.925 & 0.925 & 0.912 & 0.932 \\
\hline & Median & 0.987 & 0.987 & 0.982 & 0.990 \\
\hline & Mean & 0.998 & 0.998 & 0.997 & 0.999 \\
\hline & 3rd Quantile & 1.052 & 1.052 & 1.047 & 1.059 \\
\hline & Max. & 1.575 & 1.575 & 1.487 & 1.709 \\
\hline \multirow[t]{6}{*}{ At wave 4} & Min. & 0.588 & 0.588 & 0.559 & 0.610 \\
\hline & 1st Quantile & 0.908 & 0.908 & 0.901 & 0.914 \\
\hline & Median & 0.977 & 0.977 & 0.974 & 0.980 \\
\hline & Mean & 0.998 & 0.998 & 0.996 & 0.999 \\
\hline & 3rd Quantile & 1.065 & 1.065 & 1.059 & 1.069 \\
\hline & Max. & 1.647 & 1.647 & 1.625 & 1.737 \\
\hline \multirow[t]{6}{*}{ At wave 5} & Min. & 0.597 & 0.597 & 0.555 & 0.627 \\
\hline & 1st Quantile & 0.902 & 0.902 & 0.892 & 0.907 \\
\hline & Median & 0.977 & 0.977 & 0.973 & 0.981 \\
\hline & Mean & 0.997 & 0.997 & 0.996 & 0.998 \\
\hline & 3rd Quantile & 1.068 & 1.068 & 1.064 & 1.074 \\
\hline & Max. & 1.660 & 1.660 & 1.587 & 1.814 \\
\hline \multirow[t]{6}{*}{ At wave 6} & Min. & 0.573 & 0.573 & 0.551 & 0.604 \\
\hline & 1st Quantile & 0.877 & 0.877 & 0.861 & 0.885 \\
\hline & Median & 0.965 & 0.965 & 0.955 & 0.970 \\
\hline & Mean & 0.996 & 0.996 & 0.995 & 0.998 \\
\hline & 3rd Quantile & 1.080 & 1.080 & 1.074 & 1.084 \\
\hline & Max. & 1.801 & 1.801 & 1.697 & 1.895 \\
\hline
\end{tabular}

Note:

Stabilized weights were obtained from models using weighted sample with replicate weights

\section{Balance on time-varying confounders after adjustment by stabilized weights}

Balance on time-varying covariates is presented in Figure 7 was improved by the use of stabilized weights, but important lack of balance remains. This might have resulted from poorly specified models of the family structure transitions. Future work should focus on 
improving the knowledge of these factors.
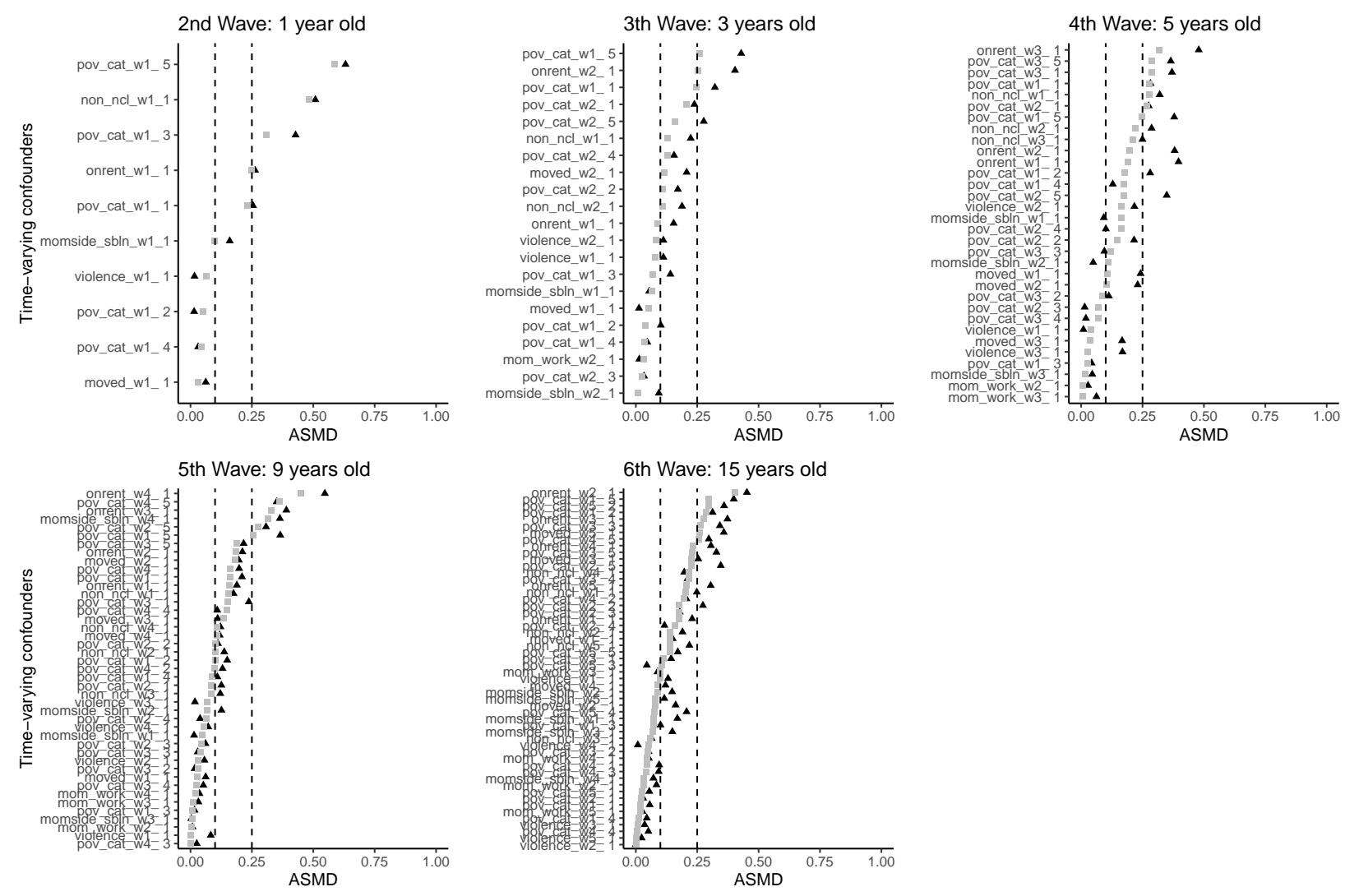

Figure 7: ASMD between Stable and Unstable Families for Time-varying Confounders at each Follow-up in the FFCWS 


\section{References}

Amato, Paul R. 2001. "Children of Divorce in the 1990s: An Update of the Amato and Keith (1991) Meta-Analysis." Journal of Family Psychology 15 (3): 355.

- 2010. "Research on Divorce: Continuing Trends and New Developments." Journal of Marriage and Family 72 (3): 650-66.

Amato, Paul R, and Bruce Keith. 1991. "Parental Divorce and the Well-Being of Children: A Meta-Analysis." American Psychological Association.

Austin, Peter C. 2016. "Variance Estimation When Using Inverse Probability of Treatment Weighting (Iptw) with Survival Analysis." Statistics in Medicine 35 (30): 5642-55.

Becker, Gary S. 1973. "A Theory of Marriage: Part I." Journal of Political Economy 81 (4): $813-46$.

Bengtson, Vern L. 2001. "Beyond the Nuclear Family: The Increasing Importance of Multigenerational Bonds: The Burgess Award Lecture." Journal of Marriage and Family 63 (1): $1-16$.

Bernardi, Fabrizio, and Diederik Boertien. 2017. "Non-Intact Families and Diverging Educational Destinies: A Decomposition Analysis for Germany, Italy, the United Kingdom and the United States." Social Science Research 63: 181-91.

Bernardi, Fabrizio, Lela Chakhaia, and Liliya Leopold. 2017. "Sing Me a Song with Social Significance': The (Mis) Use of Statistical Significance Testing in European Sociological Research." European Sociological Review 33 (1): 1-15.

Bernardi, Fabrizio, Juho Härkönen, Diederik Boertien, Linu Andersson, Kim Bastaits, and Dimitri Mortelmans. 2013. "Effects of Family Forms and Dynamics on Children's Well-Being and Life Chances: Literature Review."

Bloome, Deirdre. 2017. "Childhood Family Structure and Intergenerational Income Mobility in the United States." Demography 54 (2): 541-69. 
Bourdieu, Pierre. 1993. "A Propos de La Famille Comme Categorie Réalisée." Actes de La Recherche En Sciences Sociales, no. 100: 32-36.

Brand, Jennie E, Ravaris Moore, Xi Song, and Yu Xie. 2019. "Why Does Parental Divorce Lower Children's Educational Attainment? A Causal Mediation Analysis." Sociological Science 6: 264-92.

Brown, Susan L, Wendy D Manning, and J Bart Stykes. 2015. "Family Structure and Child Well-Being: Integrating Family Complexity." Journal of Marriage and Family 77 (1): $177-90$.

Browning, Martin, Pierre-André Chiappori, and Yoram Weiss. 2014. Economics of the Family. Cambridge University Press.

Burgette, Lane F, and Jerome P Reiter. 2010. "Multiple Imputation for Missing Data via Sequential Regression Trees." American Journal of Epidemiology 172 (9): 1070-6.

Cavanagh, Shannon E, and Paula Fomby. 2019. "Family Instability in the Lives of American Children." Annual Review of Sociology 45.

Census Bureau, U. S. 2019. "Historical Living Arrangements of Children: 1960 to Present." 2019. https://www.census.gov/library/visualizations/time-series/demo/children-historicaltime-series.html.

Cohen, Philip N. 2002. "Extended Households at Work: Living Arrangements and Inequality in Single Mothers' Employment." In Sociological Forum, 17:445-63. 3. Springer.

Cohen, Philip N, and Joanna R Pepin. 2018. "Unequal Marriage Markets: Sex Ratios and First Marriage Among Black and White Women.” Socius 4: 2378023118791084.

Coleman, James S. 1987. "Families and Schools." Educational Researcher 16 (6): 32-38.

Coontz, Stephanie. 2016. The Way We Never Were: American Families and the Nostalgia Trap. Hachette UK.

Crosnoe, Robert, Kate Chambers Prickett, Chelsea Smith, and Shannon Cavanagh. 2014. 
"Changes in Young Children's Family Structures and Child Care Arrangements." Demography 51 (2): 459-83.

Damaske, Sarah, Jenifer L Bratter, and Adrianne Frech. 2017. "Single Mother Families and Employment, Race, and Poverty in Changing Economic Times." Social Science Research 62: $120-33$.

Desmond, Matthew, and Kristin L Perkins. 2016. "Housing and Household Instability." Urban Affairs Review 52 (3): 421-36.

Downey, Douglas B, and Dennis J Condron. 2016. "Fifty Years Since the Coleman Report: Rethinking the Relationship Between Schools and Inequality." Sociology of Education 89 (3): $207-20$.

Edin, Kathryn, and Rebecca Joyce Kissane. 2010. "Poverty and the American Family: A Decade in Review." Journal of Marriage and Family 72 (3): 460-79.

Erola, Jani, and Marika Jalovaara. 2017. "The Replaceable: The Inheritance of Paternal and Maternal Socioeconomic Statuses in Non-Standard Families." Social Forces 95 (3): 971-95.

Erola, Jani, and Elina Kilpi-Jakonen. 2017. "Compensation and Other Forms of Accumulation in Intergenerational Social Inequality." In Social Inequality Across the Generations. Edward Elgar Publishing.

Esping-Andersen, Gøsta. 2016. Families in the 21st Century. SNS Förlag Stockholm.

FFCWS. 2019. "A Brief Guide to Using the Weights for Waves 1-6." Princeton University. Fisher, Julia. 2005. "Marriage Promotion Policies and the Working Poor: A Match Made in Heaven?" Boston College Third World Law Journal 25 (2): 475.

Fomby, Paula, and Andrew J Cherlin. 2007. "Family Instability and Child Well-Being." American Sociological Review 72 (2): 181-204.

Fomby, Paula, and Stefanie Mollborn. 2017. "Ecological Instability and Children's Classroom Behavior in Kindergarten.” Demography 54 (5): 1627-51. 
Fomby, Paula, and Cynthia Osborne. 2017. "Family Instability, Multipartner Fertility, and Behavior in Middle Childhood." Journal of Marriage and Family 79 (1): 75-93.

Gauthier, Jacques-Antoine, Eric D Widmer, Philipp Bucher, and Cédric Notredame. 2010. "1. Multichannel Sequence Analysis Applied to Social Science Data." Sociological Methodology 40 (1): 1-38.

Ginther, Donna K, and Robert A Pollak. 2004. "Family Structure and Children's Educational Outcomes: Blended Families, Stylized Facts, and Descriptive Regressions.” Demography 41 (4): 671-96.

Hadfield, Kristin, Margaret Amos, Michael Ungar, Julie Gosselin, and Lawrence Ganong. 2018. "Do Changes to Family Structure Affect Child and Family Outcomes? A Systematic Review of the Instability Hypothesis." Journal of Family Theory 83 Review 10 (1): 87-110.

Hadfield, Kristin, Michael Ungar, and Elizabeth Nixon. 2018. "Rethinking Discourses of Family Instability." Journal of Family Social Work 21 (2): 172-87.

Hall, Matthew, John Iceland, and Youngmin Yi. 2019. "Racial Separation at Home and Work: Segregation in Residential and Workplace Settings." Population Research and Policy Review, 1-24.

Harding, David J, Lisa Gennetian, Christopher Winship, Lisa Sanbonmatsu, and Jeffrey R Kling. 2010. "Unpacking Neighborhood Influences on Education Outcomes: Setting the Stage for Future Research." National Bureau of Economic Research.

Harris, Robby D. 2010. "A Meta-Analysis on Father Involvement and Early Childhood Social-Emotional Development." Opus Issues 2: 21-39.

Haveman, Robert, and Barbara Wolfe. 1995. "The Determinants of Children's Attainments: A Review of Methods and Findings." Journal of Economic Literature 33 (4): 1829-78.

Hällsten, Martin, and Fabian T Pfeffer. 2017. "Grand Advantage: Family Wealth and Grandchildren's Educational Achievement in Sweden." American Sociological Review 82 (2): 
$328-60$.

Härkönen, Juho. 2014. "Emerging Trends in Divorce Research.” Stockholm Research Reports in Demography 2014 (7), 1-22.

Härkönen, Juho, Fabrizio Bernardi, and Diederik Boertien. 2017. "Family Dynamics and Child Outcomes: An Overview of Research and Open Questions." European Journal of Population 33 (2): 163-84.

Hernan, M, and JM Robbins. 2017. "Causal Inference Book. 2016." Boca Raton, FL: Chapman \& Hall/CRC.

Hernán, Miguel A, and James M Robins. 2006. "Estimating Causal Effects from Epidemiological Data." Journal of Epidemiology \& Community Health 60 (7): 578-86.

Hernán, Miguel Ángel, Babette Brumback, and James M Robins. 2000. "Marginal Structural Models to Estimate the Causal Effect of Zidovudine on the Survival of Hiv-Positive Men." Epidemiology, 561-70.

Hirschman, Daniel. 2016. "Stylized Facts in the Social Sciences." Sociological Science 3: $604-26$.

Hodapp, Albert F, and Kathryn C Gerken. 1999. "Correlations Between Scores for Peabody Picture Vocabulary Test-Iii and the Wechsler Intelligence Scale for Children-Iii." Psychological Reports 84 (3_suppl): 1139-42.

Jackson, John W. 2016. "Diagnostics for Confounding of Time-Varying and Other Joint Exposures." Epidemiology (Cambridge, Mass.) 27 (6): 859.

Jacoby, Sara F, Laura Tach, Terry Guerra, Douglas J Wiebe, and Therese S Richmond. 2017. "The Health Status and Well-Being of Low-Resource, Housing-Unstable, Single-Parent Families Living in Violent Neighbourhoods in P Hiladelphia, P Ennsylvania." Health EG Social Care in the Community 25 (2): 578-89.

Jarrett, Robin L. 1994. "Living Poor: Family Life Among Single Parent, African-American 
Women." Social Problems 41 (1): 30-49.

Jeynes, William H. 2006. "The Impact of Parental Remarriage on Children: A MetaAnalysis." Marriage $\mathcal{E}$ Family Review 40 (4): 75-102.

Jæger, Mads Meier. 2012. "The Extended Family and Children's Educational Success." American Sociological Review 77 (6): 903-22.

Kang, Joseph DY, Joseph L Schafer, and others. 2007. "Demystifying Double Robustness: A Comparison of Alternative Strategies for Estimating a Population Mean from Incomplete Data." Statistical Science 22 (4): 523-39.

Kennedy, Lauren A, and Andrew Gelman. 2018. "Year 15 Fragile Families Survey Weight Adjustment."

Kingsbury, Nancy, and John Scanzoni. 2009. "Structural-Functionalism." In Sourcebook of Family Theories and Methods, 195-221. Springer.

Koot, Hans M, Edwin JCG Van Den Oord, Frank C Verhulst, and Dorret I Boomsma. 1997. "Behavioral and Emotional Problems in Young Preschoolers: Cross-Cultural Testing of the Validity of the Child Behavior Checklist/2-3." Journal of Abnormal Child Psychology 25 (3): $183-96$.

Lareau, Annette. 2011. Unequal Childhoods: Class, Race, and Family Life. Univ of California Press.

Lauster, Nathanael T. 2010. "Housing and the Proper Performance of American Motherhood, 1940-2005." Housing Studies 25 (4): 543-57.

Lee, Dohoon, and Sara McLanahan. 2015. "Family Structure Transitions and Child Development: Instability, Selection, and Population Heterogeneity." American Sociological Review 80 (4): 738-63.

Levine, Nancy E. 2008. "Alternative Kinship, Marriage, and Reproduction." Annual Review of Anthropology 37: 375-89. 
Lichter, Daniel T, Joseph P Price, and Jeffrey M Swigert. 2019. "Mismatches in the Marriage Market." Journal of Marriage and Family.

Lyngstad, Torkild Hovde. 2011. "Does Community Context Have an Important Impact on Divorce Risk? A Fixed-Effects Study of Twenty Norwegian First-Marriage Cohorts." European Journal of Population/Revue Européenne de Démographie 27 (1): 57-77.

Maldonado, Laurie C, and Rense Nieuwenhuis. 2015. "Family Policies and Single Parent Poverty in 18 Oecd Countries, 1978-2008." Community, Work E3 Family 18 (4): 395-415.

Manski, Charles F. 1993. "Identification of Endogenous Social Effects: The Reflection Problem." The Review of Economic Studies 60 (3): 531-42.

Mansournia, Mohammad Ali, Mahyar Etminan, Goodarz Danaei, Jay S Kaufman, and Gary Collins. 2017. "Handling Time Varying Confounding in Observational Research." Bmj 359: j4587.

Masarik, April S, and Rand D Conger. 2017. "Stress and Child Development: A Review of the Family Stress Model." Current Opinion in Psychology 13: 85-90.

Mathiesen, Kristin S, and Kristian Tambs. 1999. "The Eas Temperament QuestionnaireFactor Structure, Age Trends, Reliability, and Stability in a Norwegian Sample." The Journal of Child Psychology and Psychiatry and Allied Disciplines 40 (3): 431-39.

McLanahan, Sara. 2004. "Diverging Destinies: How Children Are Faring Under the Second Demographic Transition.” Demography 41 (4): 607-27.

McLanahan, Sara, Laura Tach, and Daniel Schneider. 2013. "The Causal Effects of Father Absence." Annual Review of Sociology 39: 399-427.

McShane, Blakeley B, David Gal, Andrew Gelman, Christian Robert, and Jennifer L Tackett. 2019. "Abandon Statistical Significance." The American Statistician 73 (sup1): 235-45.

McWayne, Christine, Jason T Downer, Rodrigo Campos, and Robby D Harris. 2013. "Father Involvement During Early Childhood and Its Association with Children's Early Learning: A 
Meta-Analysis." Early Education \& Development 24 (6): 898-922.

Mikolai, Júlia, and Hill Kulu. 2018. "Divorce, Separation, and Housing Changes: A Multiprocess Analysis of Longitudinal Data from England and Wales." Demography 55 (1): 83-106.

Moynihan, Daniel Patrick. 1965. "Employment, Income, and the Ordeal of the Negro Family." Daedalus, 745-70.

Nieuwenhuis, Rense, and Laurie C Maldonado. 2018. "The Triple Bind of Single-Parent Families: Resources, Employment and Policies." The Triple Bind of Single-Parent Families, 1.

Orthner, Dennis K, Hinckley Jones-Sanpei, and Sabrina A Williamson. 2003. "Family Strength and Income in Households with Children." Journal of Family Social Work 7 (2): $5-23$.

Perkins, Kristin L. 2017. "Household Complexity and Change Among Children in the United States, 1984 to 2010." Sociological Science 4: 701-24.

Pilkauskas, Natasha, and Katherine Michelmore. 2019. "The Effect of the Earned Income Tax Credit on Housing and Living Arrangements." Demography, 1-24.

Raley, R Kelly, Inbar Weiss, Robert Reynolds, and Shannon E Cavanagh. 2019. "Estimating Children's Household Instability Between Birth and Age 18 Using Longitudinal Household Roster Data." Demography, 1-17.

Reichman, Nancy E, Julien O Teitler, Irwin Garfinkel, and Sara S McLanahan. 2001. "Fragile Families: Sample and Design." Children and Youth Services Review 23 (4-5): 303-26.

Saint-Jacques, Marie-Christine, Élisabeth Godbout, Sylvie Drapeau, Toula Kourgiantakis, and Claudine Parent. 2017. "Researching Children's Adjustment in Stepfamilies: How Is It Studied? What Do We Learn?" Child Indicators Research, 1-35.

Schultz, Theodore W. 1974. "Fertility and Economic Values." In Economics of the Family: 
Marriage, Children, and Human Capital, 3-22. University of Chicago Press.

Seltzer, Judith A. 2019. "Family Change and Changing Family Demography." Demography 56 (2): 405-26.

Sharkey, Patrick, and Jacob W Faber. 2014. "Where, When, Why, and for Whom Do Residential Contexts Matter? Moving Away from the Dichotomous Understanding of Neighborhood Effects." Annual Review of Sociology 40: 559-79.

Sigle-Rushton, Wendy, and Sara McLanahan. 2004. "Father Absence and Child Well-Being: A Critical Review." The Future of the Family 116: 120-22.

Straus, Murray A. 2017. "Physical Violence in American Families: Incidence Rates, Causes, and Trends." In Abused and Battered, 17-34. Routledge.

Van Buuren, Stef, and Karin Oudshoorn. 1999. Flexible Multivariate Imputation by Mice. Leiden: TNO.

VanOrman, Alicia G, and Paola Scommegna. 2016. Understanding the Dynamics of Family Change in the United States. Population Reference Bureau.

Wells, L Edward, and Joseph H Rankin. 1991. "Families and Delinquency: A Meta-Analysis of the Impact of Broken Homes." Social Problems 38 (1): 71-93.

Wilson, William Julius. 1987. The Truly Disadvantaged: The Inner City, the Underclass, and Public Policy. University of Chicago Press. 